\title{
The driving mechanisms of particle precipitation during the moderate geomagnetic storm of 7 January 2005
}

\author{
N. Longden ${ }^{1}$, F. Honary ${ }^{1}$, A. J. Kavanagh ${ }^{1}$, and J. Manninen ${ }^{2}$ \\ ${ }^{1}$ Department of Communication Systems, Lancaster University, UK \\ ${ }^{2}$ Sodankylä Geophysical Observatory, Sodankylä, Finland
}

Received: 29 March 2007 - Revised: 20 July 2007 - Accepted: 18 September 2007 - Published: 2 October 2007

\begin{abstract}
The arrival of an interplanetary coronal mass ejection (ICME) triggered a sudden storm commencement (SSC) at 09:22 UT on the 7 January 2005. The ICME followed a quiet period in the solar wind and interplanetary magnetic field (IMF). We present global scale observations of energetic electron precipitation during the moderate geomagnetic storm driven by the ICME. Energetic electron precipitation is inferred from increases in cosmic noise absorption (CNA) recorded by stations in the Global Riometer Array (GLORIA). No evidence of CNA was observed during the first four hours of passage of the ICME or following the sudden commencement (SC) of the storm. This is consistent with the findings of Osepian and Kirkwood (2004) that SCs will only trigger precipitation during periods of geomagnetic activity or when the magnetic perturbation in the magnetosphere is substantial. CNA was only observed following enhanced coupling between the IMF and the magnetosphere, resulting from southward oriented IMF. Precipitation was observed due to substorm activity, as a result of the initial injection and particles drifting from the injection region. During the recovery phase of the storm, when substorm activity diminished, precipitation due to density driven increases in the solar wind dynamic pressure $\left(P_{\mathrm{dyn}}\right)$ were identified. A number of increases in $P_{\text {dyn }}$ were shown to drive sudden impulses (SIs) in the geomagnetic field. While many of these SIs appear coincident with CNA, SIs without CNA were also observed. During this period, the threshold of geomagnetic activity required for SC driven precipitation was exceeded. This implies that solar wind density driven SIs occurring during storm recovery can drive a different response in particle precipitation to typical SCs.
\end{abstract}

Keywords. Ionosphere (Particle precipitation) - Magnetospheric physics (Solar wind-magnetosphere interaction; Storms and substorms)

Correspondence to: N. Longden

(n.longden@lancs.ac.uk)

\section{Introduction}

Riometers enable the investigation of precipitation of energetic electrons into the D-region of the ionosphere through measurement of the absorption of cosmic noise (CNA).

One mechanism for the enhancement of precipitation in the auroral zones is the compression of the magnetosphere as a result of an increase in the dynamic pressure $\left(P_{\mathrm{dyn}}\right)$ of the solar wind (Brown et al., 1961). Compression of the magnetosphere results in the stimulation of VLF waves, which in turn drive the pitch-angle diffusion necessary for trapped particles to precipitate into the ionosphere (Perona, 1972). Magnetospheric compression can be observed as an impulsive perturbation in the horizontal component of the geomagnetic field measured on the ground; i.e. a sudden commencement (SC). When followed by a geomagnetic storm, the event is termed a sudden storm commencement (SSC), and when not a sudden impulse (SI). Conversely, when the solar wind pressure decreases the magnetosphere can experience rapid expansion. The signature of expansion is a negative sudden impulse $\left(\mathrm{SI}^{-}\right)$in the horizontal component of the geomagnetic field measured at mid to low latitudes (e.g. Takeuchi et al., 2002).

Precipitation driven by a SC can be observed by riometers as short-lived CNA coincident with the onset of the SC, known as Sudden Commencement Absorption (SCA) (Brown et al., 1961). CNA observed following an SI is termed Sudden Impulse Absorption (SIA). When observed, SCA and SIA exhibit a geomagnetic latitude and local time dependency, with probability of occurrence maximising around local noon between $65^{\circ}$ and $70^{\circ}$ magnetic latitude (Perona, 1972). Osepian and Kirkwood (2004) have determined that a storm SC event during a period of activity, defined as a period when the geomagnetic index $K_{p}$ is two or greater, will result in SCA proportional to the magnitude of the magnetic impulse observed at equatorial latitudes. However, a storm SC event during a period of quiet activity $\left(K_{p}<2\right)$ would only result in SCA if the magnitude of the

Published by Copernicus Publications on behalf of the European Geosciences Union. 
magnetic impulse exceeded a threshold of around $30 \mathrm{nT}$. In their study, SCA was evident during active periods irrespective of the local time of the observing riometer. However, at quiet times, the local time sector altered the threshold of magnetic field perturbation required for SCA to occur, with a greater perturbation required for SCA in the local afternoon than local morning.

Magnetospheric compression has been linked to substorm processes, such as reducing the period of southward IMF required for substorm activity to occur (Burch, 1972) and the triggering of substorms (Brown, 1978). Precipitation due to substorms has been linked to a number of forms of CNA (e.g. Stauning, 1996, and references therein), including CNA around local midnight, presumably close to the injection region of the substorm, and in the morning sector, due to the drift of injected electrons.

Interplanetary Coronal Mass Ejections (ICME) are the interplanetary (IP) counterpart of Coronal Mass Ejections (CME). When earthward directed, ICMEs are known to drive geomagnetic storms with levels of activity ranging from the most intense storms observed (Richardson et al., 2001) to relative inactivity (Gosling et al., 1991). Taylor et al. (1994) have shown that ICMEs are the most likely drivers for SSC events.

In this paper we study the global-scale effects on particle precipitation of a moderate geomagnetic storm triggered by an ICME that collided with the magnetosphere on 7 January 2005 and consider the effects in the context of the survey of SSC-related absorption by Osepian and Kirkwood (2004). The ICME followed a period of low activity in both the solar wind and magnetosphere indicating little energy coupling into the system. The storm developed over the course of two days and exhibited at least two periods of substorm activity, observed by the Los Alamos National Laboratory (LANL) satellites at geosynchronous orbit. The recovery phase of the storm on the 8 January 2005 was accompanied by a number of solar wind density-driven sudden impulses that led to precipitation confined mostly to the dayside magnetosphere. There was an advantageous configuration of riometers with coverage of both magnetic noon and midnight at the time of the sudden commencement and during a good portion of the recovery phase of the storm making this an interesting case study on the effects of an ICME on energetic electron precipitation on global scales.

\section{Instrumentation}

Observations of the solar wind and IMF during the event are taken from the ACE satellite, in orbit around the L1 point, and the Geotail satellite. During this event, Geotail was located off the dawn flank moving towards noon close to the Earth. The solar wind velocities and magnetic structure observed by the ACE satellite are consistent with those observed by Geotail, indicating that Geotail is located outside the bow shock and magnetosphere, directly in the solar wind throughout this event. The IMF data are obtained from the ACE magnetic fields experiment (MAG) instrument (Smith et al., 1998) and the Geotail Magnetic Field Measurement (MGF) instrument (Kokubun et al., 1994). The ACE solar wind data are obtained from the Solar Wind Electron Proton Alpha Monitor (SWEPAM) instrument (McComas et al., 1998) and the Geotail solar wind data are obtained from the Comprehensive Plasma Instrument (CPI) (Frank et al., 1994).

The global scale effects of the ICME in the ionosphere were investigated using two riometer chains; the NORSTAR riometer chain (formerly CANOPUS), covering CANADA, and the SGO riometer chain in Fennoscandia. Data from the central beam (beam 25) of the imaging riometer (IRIS) located at Kilpisjärvi was also used. These riometers are detailed in Table 1 and form part of the GLORIA project (Global Riometer Array). Magnetic latitudes are given in the Corrected Geomagnetic (CGM) coordinate system using the International Geomagnetic Reference Field (IGRF) model for 2005 (e.g. Maus et al., 2005). GLORIA aims to link the data from riometers located throughout the Northern and Southern Hemispheres to enable investigation of the effect of electron precipitation simultaneously across the globe. Small errors in the calculation of the quiet day curves for the riometers at Abisko and Rovaniemi could result in errors of the absolute magnitude of CNA of the order of 0.1 to $0.2 \mathrm{~dB}$ during this event.

The geomagnetic field local to the riometers was investigated using data from ground based magnetometers. The IMAGE magnetometer chain is located close to the SGO chain of riometers and the CARISMA magnetometer chain (formerly CANOPUS) is located close to the NORSTAR riometers. Three of the magnetometer stations used are not located in the region of one of the riometers detailed in Table 1. These are at Muonio (station code MUO), Rørvik (station code RVK) and Oulujärvi (station code OUJ). These stations have a geographic latitude and longitude of $68.02^{\circ} \mathrm{N}$, $23.53^{\circ} \mathrm{E}, 64.94^{\circ} \mathrm{N}, 10.98^{\circ} \mathrm{E}$ and $64.52^{\circ} \mathrm{N}, 27.23^{\circ} \mathrm{E}$ respectively. Pi2 pulsations were investigating using the lowest latitude CARISMA station (Pinawa) and the York magnetometer (station code YOR) from the SAMNET magnetometer chain, located at $53.95^{\circ} \mathrm{N}, 1.05^{\circ} \mathrm{W}$ (geographic).

Geosynchronous particle flux intensity measurements are taken from the Synchronous Orbit Particle Analyzer (SOPA) instrument (Belian et al., 1992) on board the LANL satellites. At the time of the ICME, data was available from five LANL satellites with SOPA instrumentation; 084, 095, 97A, $01 \mathrm{~A}$ and $02 \mathrm{~A}$. These satellites were located at geographic longitudes of $166.13^{\circ} \mathrm{W}, 38.54^{\circ} \mathrm{W}, 145.36^{\circ} \mathrm{E}, 8.16^{\circ} \mathrm{E}$ and $69.30^{\circ} \mathrm{E}$, respectively, during this event. Figure 1 indicates the geographic location of the GLORIA riometers used in this study. The geographic longitude of the five LANL satellites are shown in red. 


\section{Observations of the ICME in the solar wind}

At approximately 08:42 UT on the 7 January 2005 , the signature of an ICME was first observed in the solar wind and IMF data from the ACE satellite at the L1 point. Figure 2 shows the solar wind and IMF data observed by ACE and Geotail on the 7 and 8 January 2005. Panels (a) to (c) show the IMF total magnetic field strength, the magnetic field strength component in the $\mathrm{Y}$ direction GSM (East-West), and the magnetic field strength component in the Z direction GSM (North-South), respectively. Panels (d) and (e) give the solar wind velocity in the $\mathrm{X}$ direction GSM and the proton number density in the solar wind from both satellites. Panel (f) displays the solar wind dynamic pressure from Geotail only and panel (g) shows the ratio between the helium alpha number density and the proton number density in the solar wind from ACE only. The ICME arrival was evident at Geotail at $\sim 09: 24$ UT, indicated by the vertical line on Fig. 2. Solar wind conditions returned to ambient levels by the 9 January 2005.

Comparison of the IMF data from ACE and Geotail indicates a consistent magnetic structure in the solar wind. The best cross-correlation between the datasets of the satellites is achieved when the ACE data are delayed by $\sim 42.6 \mathrm{~min}$. The ACE data given in Fig. 2 has been shifted in time by this amount. This value is close to the mean delay time between the satellites of $\sim 45 \mathrm{~min}$, calculated according to their separation and the velocity of the solar wind (e.g. Khan and Cowley, 1999). The ACE solar wind data are unavailable for the period from $\sim 20: 59$ UT ( $\sim 21: 41$ UT at Geotail) on the 7 January to $\sim 03: 11$ UT ( $\sim 03: 53$ UT at Geotail) on the 8 January 2005 whereas the Geotail solar wind dataset is complete. Data from both satellites are shown as ACE provides information about the helium alpha particle content of the solar wind.

With the onset of the ICME, the solar wind velocity increases from approximately $500 \mathrm{~km} \mathrm{~s}^{-1}$ to $600 \mathrm{~km} \mathrm{~s}^{-1}$. This is followed by a decrease to pre-ICME levels over the duration of the event. The IMF exhibits two periods of extended southward orientation, the first between $\sim 13: 38$ and $\sim 15: 47$ UT on the 7 January and the second between $\sim 21: 41$ UT on the 7 January and $\sim 02: 00$ UT on the 8 January. The $P_{\text {dyn }}$ is highly variable and elevated from ambient levels throughout the event, during periods of both northward and southward IMF. It should be noted that the $P_{\mathrm{dyn}}$ is calculated for Geotail CPI assuming that the helium alpha particle number density of the solar wind is constantly $5 \%$ of the proton number density. From the limited data set available from ACE SWEPAM, it can be seen that the ratio of helium alpha number density to proton number density exceeds this for extended periods throughout the event, reaching levels of approximately 0.34 . Therefore, the $P_{\text {dyn }}$ will at times be underestimated in the Geotail data set.

\section{Observations of the SSC}

At $\sim 09: 22$ UT on 7 January, a global scale SC signature was identified in ground based magnetometer readings in the Northern Hemisphere, confirmed by the NOAA NGDC (National Oceanic and Atmospheric Administration National Geophysical Data Center ${ }^{1}$ ). The SC signature was identified in mid to low latitude ground based magnetometers. The magnitude of the perturbation of the horizontal component of the geomagnetic field ranged from $-4 \mathrm{nT}$ to $-6.6 \mathrm{nT}$ at stations from the SAMNET array. The SC was initiated by the step increase in the $P_{\mathrm{dyn}}$ at the start of the ICME as the velocity of the solar wind rises sharply.

Of the ten stations that recorded the $\mathrm{SC}$, four magnetometers recorded a class B event (defined as "Fair, ordinary but unmistakable" by the NOAA) while the six remaining magnetometers recorded a class $\mathrm{C}$ event (defined as "Very poor, doubtful observation"). The magnetometers located at magnetic latitudes of $\sim 47^{\circ} \mathrm{N}$ and above recorded a preliminary reverse impulse (PRI) where the magnetic perturbation was observed to decrease before the main positive impulse (MI), determined as the SC* signature by Araki (1977). Below these latitudes, the standard SC signature of a positive impulse only was observed by the magnetometer stations. The stations at which the SC signature was observed are detailed in Table 2.

Quiet conditions were observed prior to the SC; the $K_{p}$ index did not exceed a value of $0^{+}$between 00:00 and 09:00 UT on the 7 January 2005. This suggests that the magnetosphere was in a relatively unprimed state before the arrival of the ICME. We define unprimed as without sufficient trapped particles for precipitation to be identified in riometer CNA. The $K_{p}$ index on the 7 and 8 January 2005 is shown in the top panel of Fig. 3.

The SC was followed by a moderate geomagnetic storm; the definition of a moderate storm as when minimum $D_{s t}$ falls in the range of -50 to $-100 \mathrm{nT}$ (Gonzalez et al., 1994) has been used. The $D_{s t}$ index during the 7 and 8 January 2005 is given in the second panel of Fig. 3. It should be noted that $D_{s t}$ is not the most appropriate index with which to identify certain types of geomagnetic activity. Fast solar wind streams, for example, cause little deflection in $D_{s t}$ but still input significant energy to the system (e.g. Borovsky and Denton, 2006; Denton et al., 2006). However, $D_{s t}$ is considered an appropriate index to use in the identification of ICME driven storms.

The storm develops in two phases with partial recovery between minima; Kamide et al. (1998) termed this a type 2 storm as opposed to a sharp decrease in $D_{s t}$ and a gradual recovery (type 1). The first $D_{s t}$ minimum occurs at 16:00 UT on the 7 January, with a magnitude of $-46 \mathrm{nT}$. It should be

\footnotetext{
${ }^{1}$ ftp://ftp.ngdc.noaa.gov/STP/SOLAR_DATA/RELATED_ INDICES/Geomagnetic_PDF_Files/Geomagnetic_Storm_Sudden_ Commencements_0501.pdf
} 
Table 1. GLORIA stations used in this study ordered by descending magnetic latitude.

\begin{tabular}{|c|c|c|c|c|c|c|}
\hline Code & Station & Geographic Latitude & Geographic Longitude & Magnetic Latitude & MLT (at 00:00 UT) & L Shell \\
\hline TAL & Taloyoak & $69.54^{\circ} \mathrm{N}$ & $93.56^{\circ} \mathrm{W}$ & $78.59^{\circ} \mathrm{N}$ & $\sim 17: 19$ & \\
\hline $\mathrm{CON}$ & Contwoyto & $65.75^{\circ} \mathrm{N}$ & $111.26^{\circ} \mathrm{W}$ & $73.00^{\circ} \mathrm{N}$ & $\sim 15: 43$ & 11.86 \\
\hline RAN & Rankin Inlet & $62.82^{\circ} \mathrm{N}$ & $92.11^{\circ} \mathrm{W}$ & $72.53^{\circ} \mathrm{N}$ & $\sim 17: 35$ & 11.25 \\
\hline $\mathrm{FCH}$ & Fort Churchill & $58.76^{\circ} \mathrm{N}$ & $94.09^{\circ} \mathrm{W}$ & $68.62^{\circ} \mathrm{N}$ & $\sim 17: 28$ & 7.63 \\
\hline RAB & Rabbit Lake & $58.23^{\circ} \mathrm{N}$ & $103.68^{\circ} \mathrm{W}$ & $67.08^{\circ} \mathrm{N}$ & $\sim 16: 37$ & 6.68 \\
\hline KIL & Kilpisjärvi & $69.05^{\circ} \mathrm{N}$ & $20.79^{\circ} \mathrm{E}$ & $65.98^{\circ} \mathrm{N}$ & $\sim 02: 44$ & 6.12 \\
\hline DAW & Dawson & $64.05^{\circ} \mathrm{N}$ & $139.11^{\circ} \mathrm{W}$ & $65.92^{\circ} \mathrm{N}$ & $\sim 13: 32$ & 6.09 \\
\hline $\mathrm{ABK}$ & Abisko & $68.40^{\circ} \mathrm{N}$ & $18.90^{\circ} \mathrm{E}$ & $65.41^{\circ} \mathrm{N}$ & $\sim 02: 31$ & 5.86 \\
\hline IVA & Ivalo & $68.55^{\circ} \mathrm{N}$ & $27.28^{\circ} \mathrm{E}$ & $65.17^{\circ} \mathrm{N}$ & $\sim 02: 59$ & 5.75 \\
\hline SOD & Sodankylä & $67.42^{\circ} \mathrm{N}$ & $26.39^{\circ} \mathrm{E}$ & $64.06^{\circ} \mathrm{N}$ & $\sim 02: 53$ & 5.30 \\
\hline ROV & Rovaniemi & $66.78^{\circ} \mathrm{N}$ & $25.94^{\circ} \mathrm{E}$ & $63.42^{\circ} \mathrm{N}$ & $\sim 02: 50$ & 5.07 \\
\hline OUL & Oulu & $65.09^{\circ} \mathrm{N}$ & $25.89^{\circ} \mathrm{E}$ & $61.69^{\circ} \mathrm{N}$ & $\sim 02: 47$ & 4.51 \\
\hline PIN & Pinawa & $50.20^{\circ} \mathrm{N}$ & $96.04^{\circ} \mathrm{W}$ & $60.24^{\circ} \mathrm{N}$ & $\sim 17: 22$ & 4.12 \\
\hline JYV & Jyväskylä & $62.42^{\circ} \mathrm{N}$ & $25.28^{\circ} \mathrm{E}$ & $58.95^{\circ} \mathrm{N}$ & $\sim 02: 40$ & 3.81 \\
\hline
\end{tabular}

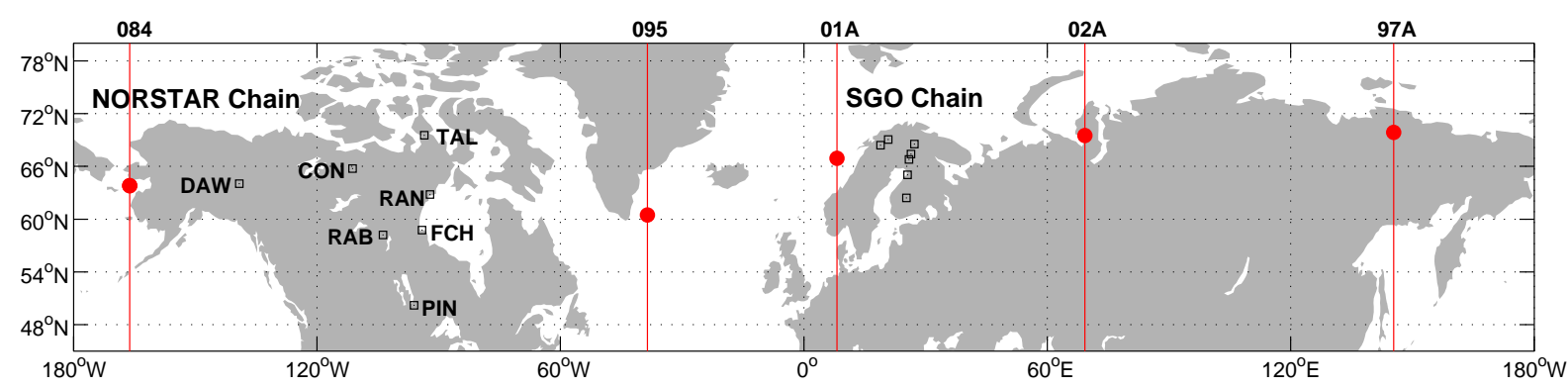

Fig. 1. Geographic location of the GLORIA stations used in this study. The geographic longitude of the five LANL satellites in orbit on the 7 January 2005 are shown in red for all riometer latitudes. Red dots indicate the approximate footprint of a geomagnetic field line mapped from the equator at $6.6 R_{E}$ at the longitude of each of the LANL satellites. The field line mapping was performed using the Tsyganenko $89 \mathrm{C}$ model (Tsyganenko, 1995).

noted that $D_{s t}$ also reaches the value of $-46 \mathrm{nT}$ at 18:00 UT after a slight recovery at 17:00 UT. The second $D_{s t}$ minimum occurs at 02:00 UT on the 8 January, with a magnitude of $-96 \mathrm{nT}$. Between the two minima, the $D_{s t}$ recovers to $-34 \mathrm{nT}$ at 21:00 UT on the 7 January, a recovery of $12 \mathrm{nT}$.

From observations of the onset of the decline in $D_{s t}$ prior to each minimum, it can be inferred that ring current enhancement begins between 14:00 and 15:00 UT and again between 22:00 and 23:00 UT. As Geotail shows extended negative $B_{z}$ from $\sim 13: 38$ UT until $\sim 15: 47 \mathrm{UT}$ and from $\sim 21: 41$ UT on the 7 January 2005 until $\sim 02: 00$ UT on the 8 January 2005 it, therefore, seems probable in this case that the two phase development of the storm is linked to the two significant periods of southward IMF in the ICME passage. Prior to the second enhancement, the storm would have been classified as small or weak, i.e. $D_{s t}>-50 \mathrm{nT}$ (Gonzalez et al., 1994).

The third panel of Fig. 3 presents the SYM-H index. The SYM-H index can be considered a high-resolution $D_{s t}$ index
(Wanliss and Showalter, 2006) and is derived from the horizontal component of the geomagnetic field recorded at six mid to low latitude ground based magnetometers. As it provides one minute resolution, this index can be used to investigate the effects of $P_{\text {dyn }}$ pulses (e.g. Takeuchi et al., 2002). The quick look values for the upper and lower auroral electrojet indices (AU and AL, respectively) are given in the bottom two panels of Fig. 3.

Figure 4 shows the electron flux intensity measured by the SOPA instrument on the LANL satellites during the period of the 7 and 8 January 2005. The flux intensity is given for energy channels in the range of 50 to $500 \mathrm{keV}$. From top to bottom, the panels show the electron flux recorded by the LANL-97A, 084, 095, 01A and 02A satellites. The magnetic local times (MLT) for these satellites at 00:00 UT are $\sim 09: 19, \sim 12: 31, \sim 21: 03, \sim 00: 09$ and $\sim 04: 11$, respectively.

During the storm, two periods of substorm activity with multiple particle injections were identified in the electron flux intensity at geosynchronous orbit. The LANL SOPA 
Table 2. Magnetometer stations recording an SC signature at 09:22 UT on 7 January 2005, ordered by descending magnetic latitude.

\begin{tabular}{|c|c|c|c|c|c|c|}
\hline Code & Station & Geographic Latitude & Geographic Longitude & Magnetic Latitude & Class & SC Type \\
\hline LER & Lerwick & $60.13^{\circ} \mathrm{N}$ & $1.18^{\circ} \mathrm{W}$ & $57.92^{\circ} \mathrm{N}$ & $\mathrm{B}$ & $\mathrm{SC}^{*}$ \\
\hline NUR & Nurmijärvi & $60.50^{\circ} \mathrm{N}$ & $24.65^{\circ} \mathrm{E}$ & $56.97^{\circ} \mathrm{N}$ & $\mathrm{C}$ & $\mathrm{SC}^{*}$ \\
\hline ESK & Eskdalemuir & $55.32^{\circ} \mathrm{N}$ & $3.20^{\circ} \mathrm{W}$ & $52.57^{\circ} \mathrm{N}$ & $\mathrm{B}$ & $\mathrm{SC}^{*}$ \\
\hline HAD & Hartland & $50.99^{\circ} \mathrm{N}$ & $4.48^{\circ} \mathrm{W}$ & $47.44^{\circ} \mathrm{N}$ & $\mathrm{B}$ & $\mathrm{SC}^{*}$ \\
\hline BDV & Budkov & $49.08^{\circ} \mathrm{N}$ & $14.02^{\circ} \mathrm{E}$ & $44.43^{\circ} \mathrm{N}$ & $\mathrm{C}$ & $\mathrm{SC}$ \\
\hline MMB & Memambetsu & $43.91^{\circ} \mathrm{N}$ & $144.19^{\circ} \mathrm{E}$ & $37.26^{\circ} \mathrm{N}$ & $\mathrm{C}$ & $\mathrm{SC}$ \\
\hline SPT & San Pablo Toledo & $39.55^{\circ} \mathrm{N}$ & $4.35^{\circ} \mathrm{W}$ & $32.10^{\circ} \mathrm{N}$ & $\mathrm{C}$ & SC \\
\hline KAK & Kakioka & $36.23^{\circ} \mathrm{N}$ & $140.19^{\circ} \mathrm{E}$ & $29.46^{\circ} \mathrm{N}$ & $\mathrm{C}$ & $\mathrm{SC}$ \\
\hline KNY & Kanoya & $31.42^{\circ} \mathrm{N}$ & $130.88^{\circ} \mathrm{E}$ & $24.85^{\circ} \mathrm{N}$ & $\mathrm{C}$ & $\mathrm{SC}$ \\
\hline GUI & Guima & $28.32^{\circ} \mathrm{N}$ & $16.44^{\circ} \mathrm{W}$ & $13.03^{\circ} \mathrm{N}$ & $\mathrm{B}$ & SC \\
\hline
\end{tabular}

Solar Wind and IMF Data: 7 to 8 January 2005

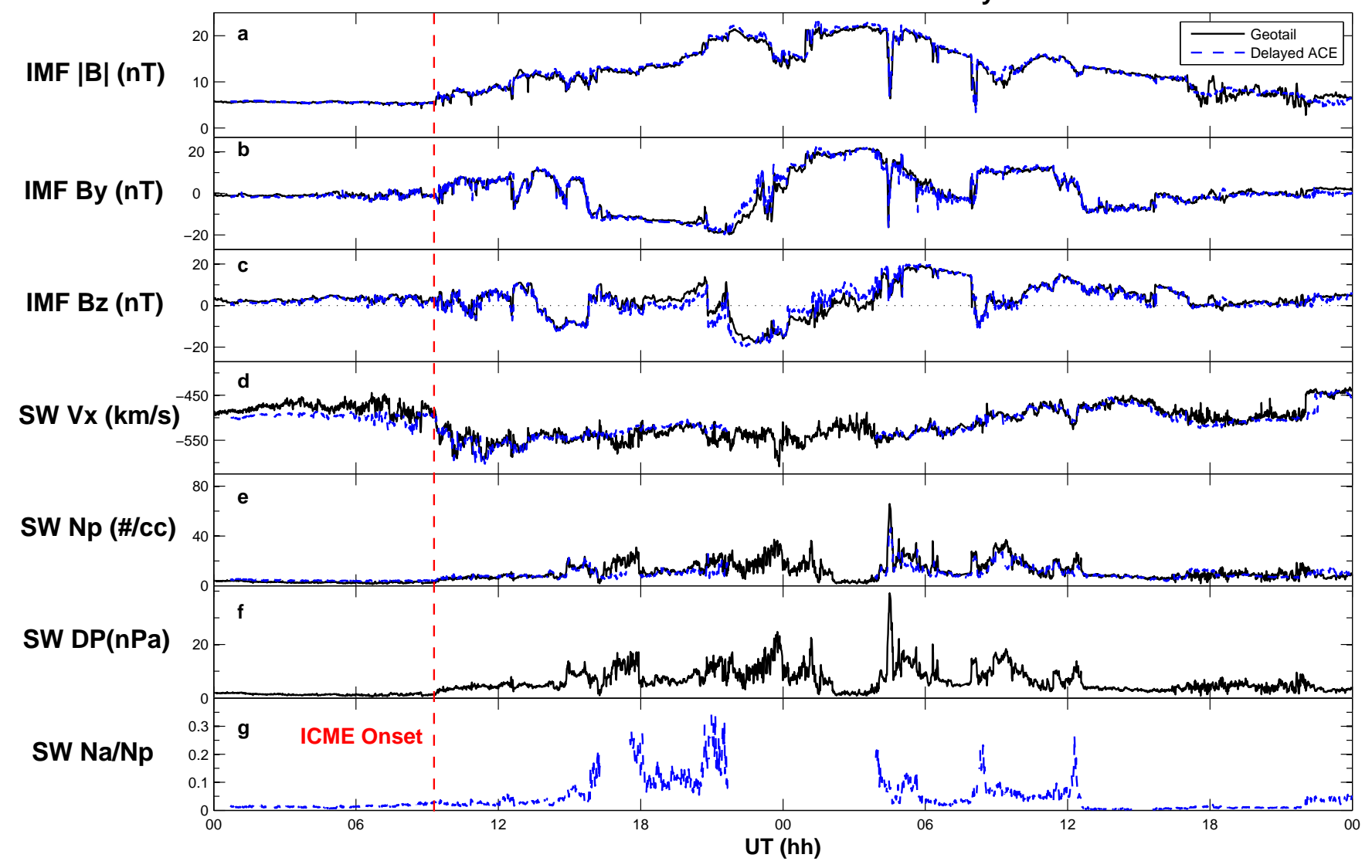

7 January 2005

8 January 2005

Fig. 2. Solar Wind and Interplanetary Magnetic Field Data from the ACE and Geotail satellites on the 7 and 8 January 2005. ACE data has been adjusted to the time of observation at Geotail. From (a) to (g), the panels show total magnetic field strength of the IMF, IMF $B_{y}$ GSM, IMF $B_{z}$ GSM, solar wind speed in X direction GSM, solar wind proton number density, solar wind dynamic pressure and the ratio between helium number density and proton number density in the solar wind. 


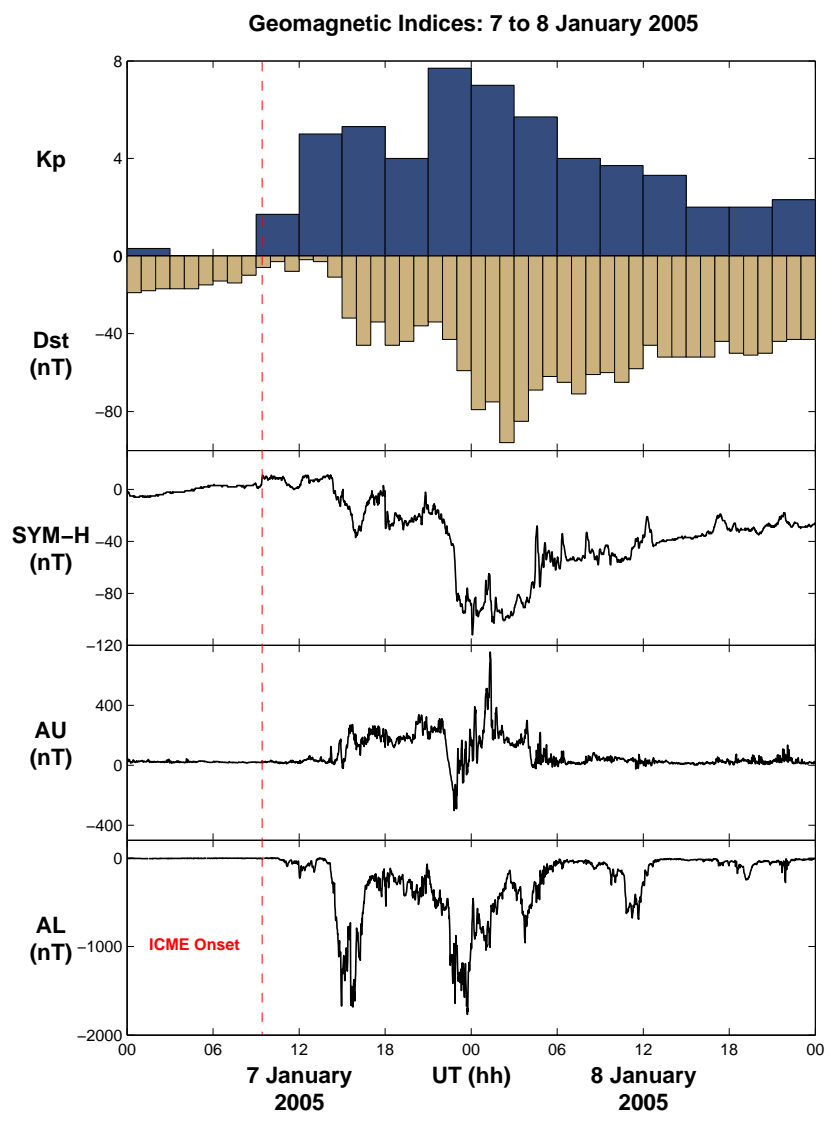

Fig. 3. Geomagnetic indices on the 7 and 8 January 2005. From top to bottom, the panels show the $K_{p}$ index, the $D_{s t}$ index, the $\mathrm{SYM}-\mathrm{H}$ index, the AU index and the AL index.

data during the onset of the first period of substorm activity is shown in Fig. 5a, covering the period of 14:00 UT to 15:15 UT on the 7 January 2005. From Fig. 5a, the injection signature of a substorm is evident in the electron flux data of LANL-97A at $\sim 14: 12$ UT. At this time, the satellite was located at an MLT of $\sim 23: 56$, inside the injection region. After approximately three minutes, the onset of a dispersed injection signature of drifting electrons was observed in the electron flux of LANL-084, located at $\sim 03: 12$ MLT. The dispersed signature results from electrons with different energies orbiting at different velocities away from the injection region; the drift velocity of a particle is directly proportional to its energy (e.g. Hargreaves, 1992). Both satellites show evidence of a second enhancement in electron flux at $\sim 14: 53$ UT.

This substorm activity follows the first decrease in $D_{s t}$, after 14:00 UT, and a southward turning of the IMF. Conditions remain disturbed following the substorm onset. Large enhancements of electron flux are not evident after $\sim 16: 43 \mathrm{UT}$, although depletions can be seen at later times by LANL-97A and $02 \mathrm{~A}$.
A seemingly dispersionless injection can be seen in the electron flux intensity at LANL-02A at $\sim 22: 27$ UT on 7 January ( 02:39 MLT), indicating the onset of the second period of substorm activity at this time. The electron flux intensity from the LANL SOPA instruments between 22:15 UT and 23:30 UT on the 7 January 2005 are shown in Fig. 5b. This activity follows the second decrease in $D_{s t}$, occurring between 22:00 UT and 23:00 UT, and a period of southward IMF. This was followed by more activity at around 22:50 UT, with a seemingly dispersionless injection signature at LANL$095(\sim 19: 53$ MLT $)$ and 01A ( 22:59 MLT $)$ at this time. The dispersed signature of drifting electrons is evident at LANL02A ( 03:00 MLT). A clear injection signature can also be seen at LANL-095 at $\sim 03: 33$ UT on the 8 January 2005 ( $\sim 00: 35 \mathrm{MLT})$, with dispersed signatures evident at the other satellites. The geosynchronous electron flux intensity during this injection is shown in Fig. 5c.

\section{Observations of particle precipitation}

The ionospheric CNA data observed by seven of the SGO riometers and IRIS at Kilpisjärvi throughout the ICME event is shown in Fig. 6a. From top to bottom, the plots relate to these stations ordered by descending geomagnetic latitude. The SGO riometers and IRIS have operating frequencies in the range $29.9 \mathrm{MHz}$ to $38.2 \mathrm{MHz}$. As frequency can be considered to be a scaling factor for absorption magnitude (e.g. Hargreaves, 1969), all absorption data have been scaled to a frequency of $30 \mathrm{MHz}$. The scaling was performed according to Eq. (1), where $f_{30}$ is a frequency of $30 \mathrm{MHz}, f_{o}$ is the operational frequency of the riometer and $A$ is the absorption at a given frequency.

$A\left(f_{30}\right)=A\left(f_{o}\right) \frac{\left(f_{o}\right)^{2}}{\left(f_{30}\right)^{2}}$

Figure $6 \mathrm{~b}$ shows the CNA data for the event from seven of the NORSTAR riometers. From top to bottom, the plots relate to these stations ordered by descending geomagnetic latitude. All NORSTAR riometers have a frequency of $30 \mathrm{MHz}$. The vertical lines on Fig. 6 indicate the timing of the SC, at $\sim 09: 22$ UT, and the onset of two substorms, at $\sim 14: 12$ UT and $\sim 22: 27$ UT, for both the SGO riometers and IRIS and the NORSTAR riometers.

\subsection{Precipitation prior to substorm onset}

The GLORIA riometers provided simultaneous dayside and nightside coverage of the ionosphere at the time of the SC. The SGO and IRIS riometers were around local noon, in a suitable position for the detection of SCA. The NORSTAR riometers were located in the night sector (22:50-03:00 MLT) and so would be less likely to observe precipitation effects (e.g. Ortner et al., 1962; Brown et al., 1972). No significant CNA is detected by any of the riometers following the SC. The absence of SCA is expected as the 


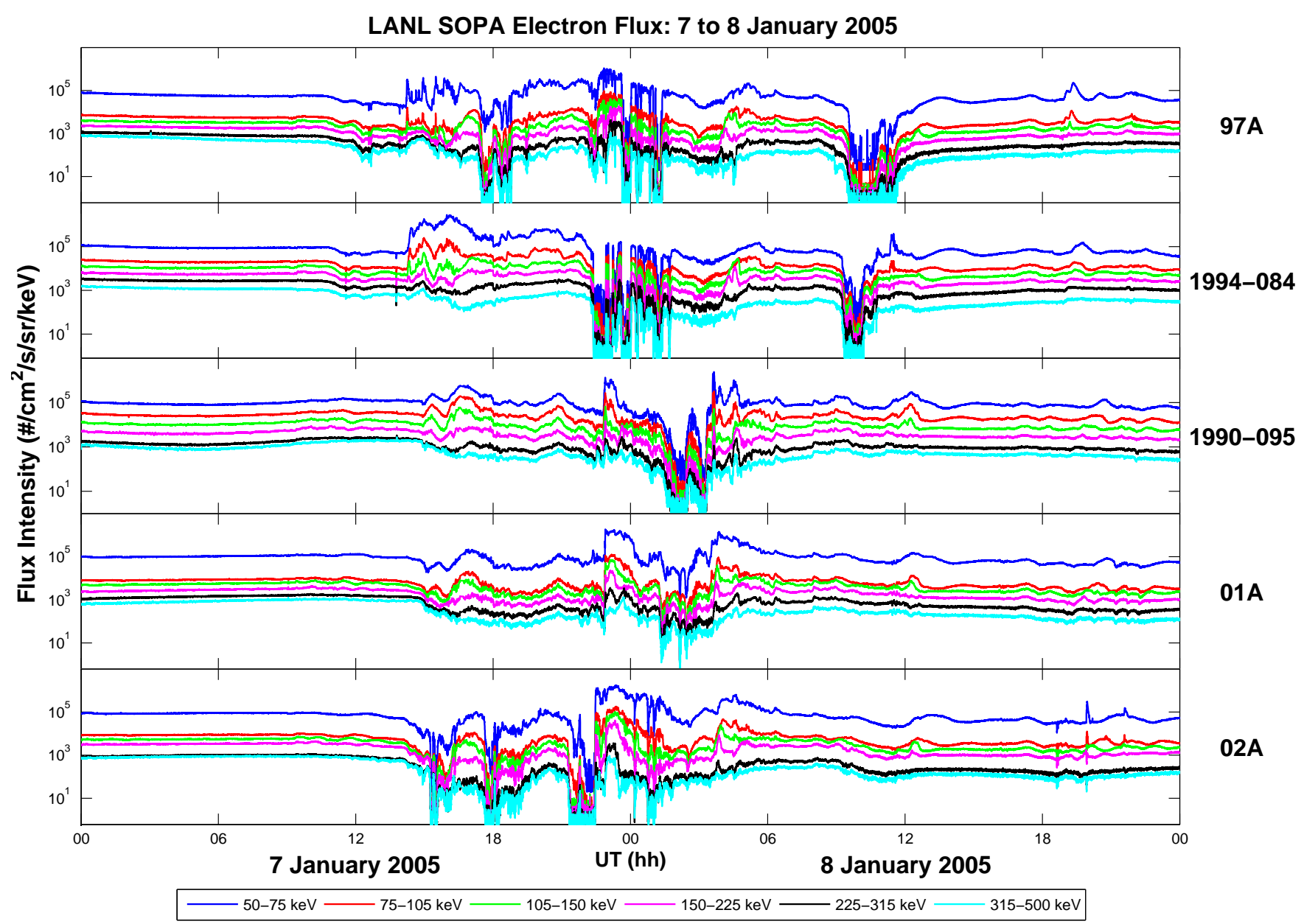

Fig. 4. Electron flux for particles with energies in the range of 50 to $500 \mathrm{keV}$ from the LANL satellites used in the study on the 7 and 8 January 2005.

conditions for SCA (Osepian and Kirkwood, 2004) are not met; $K_{p}<2$ and geomagnetic perturbation $<30 \mathrm{nT}$.

During the first fours hours of passage of the ICME, prior to the onset of the first substorm at $\sim 14: 12$ UT on 7 January, CNA is limited. The majority of the riometers show only small fluctuations in CNA of the order of $0.15 \mathrm{~dB}$, which is consistent with CNA fluctuations prior to the ICME. A step increase of $\sim 0.22 \mathrm{~dB}$ can be seen at Abisko at $\sim 14: 05$ UT on 7 January, although this is most likely to be due to the small error in CNA calculation stated in Sect. 2. Isolated instances of CNA are evident at this time at Rabbit Lake, up to $\sim 0.63 \mathrm{~dB}$, and at Dawson, of the order of $0.3 \mathrm{~dB}$.

The horizontal component of the geomagnetic field recorded by ground based magnetometer stations in the IMAGE chain (panel a) and the CARISMA chain (panel b) are shown in Fig. 7. The plots show the stations ordered by descending magnetic latitude. The bottom panels show the horizontal magnetic field component of the SAMNET York sta- tion and the CARISMA Pinawa station filtered for Pi2 pulsations. The data show that there is little geomagnetic activity in the period prior to substorm onset. The vertical lines mark the time of the SC and the onset of the two substorm periods.

\subsection{Precipitation during the first period of substorm activity}

At the time of onset of the first period of substorm activity ( $\sim 14: 12$ UT on the 7 January 2005$)$, the NORSTAR riometer stations are in the local morning ( 03:44-07:47 MLT) and the SGO riometers and IRIS are located towards dusk ( 16:43-17:11 MLT). Figure 8 shows the CNA data for the event from 14:00 UT until 22:00 UT on the 7 January 2005, covering this period of activity. Figure 9a shows the IMAGE magnetometer data during this period.

Dawson, the most westerly NORSTAR station, observes CNA from $\sim 14: 16$ UT $(\sim 03: 44$ MLT). The CNA is sustained, not reaching pre-onset levels until $\sim$ 18:03 UT, and reaches levels above $4 \mathrm{~dB}$. A further three stations, Rabbit 


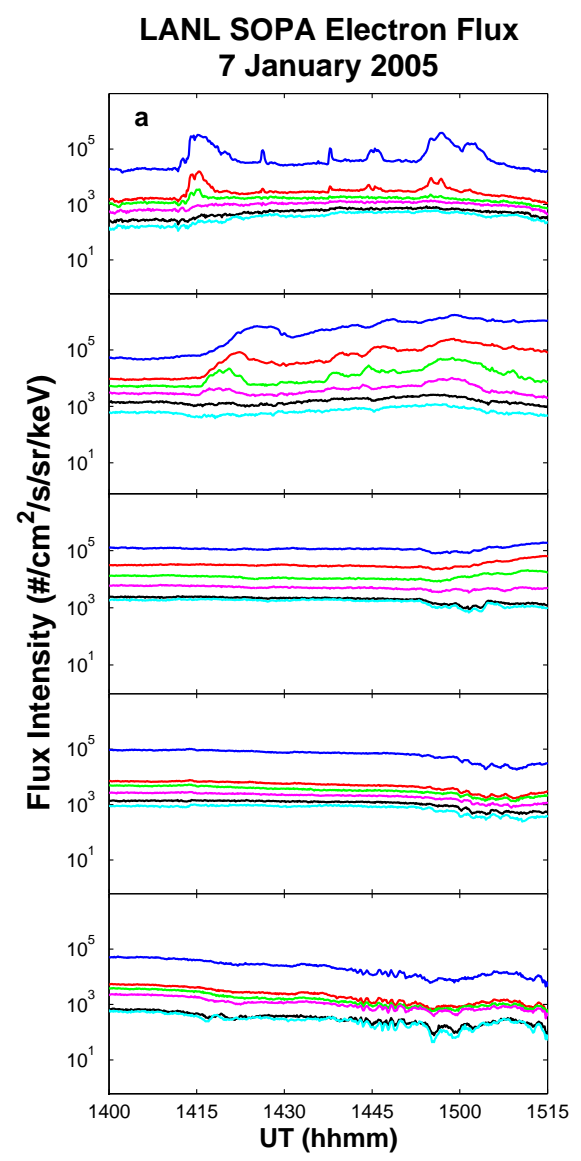

LANL SOPA Electron Flux 7 January 2005

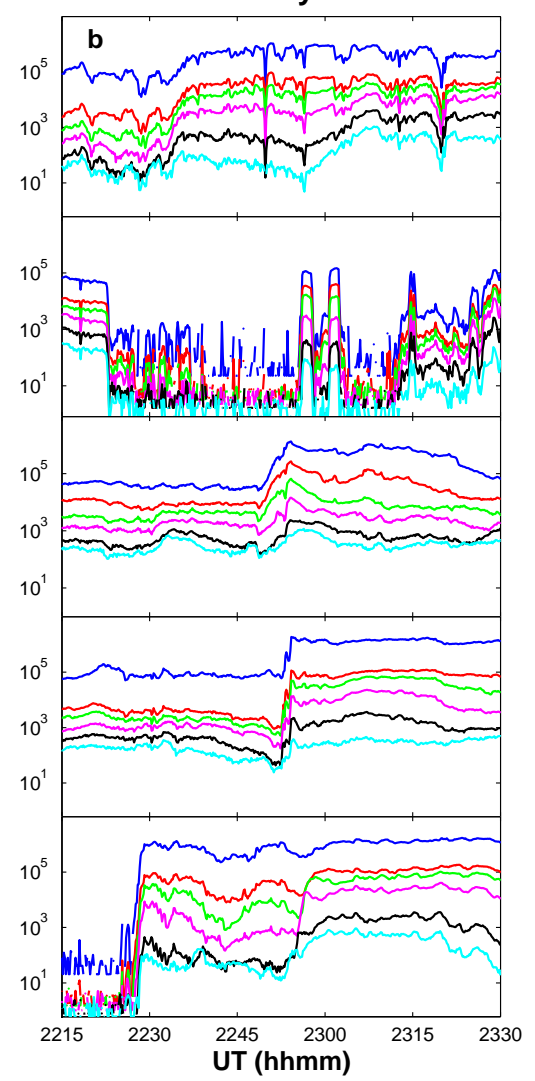

LANL SOPA Electron Flux 8 January 2005

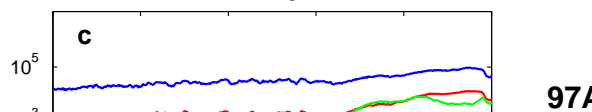

97A

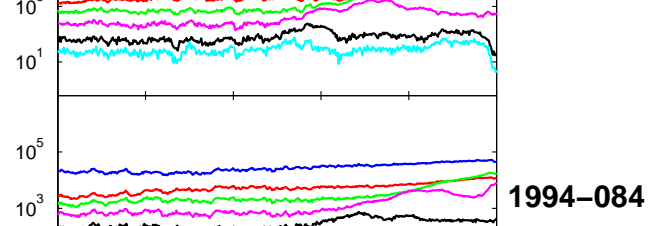

$10^{1}$

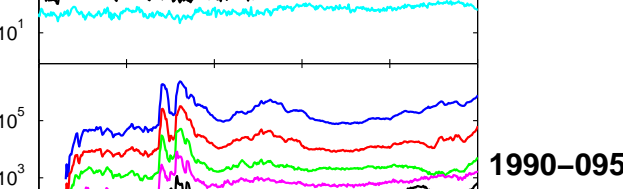

$10^{1}$

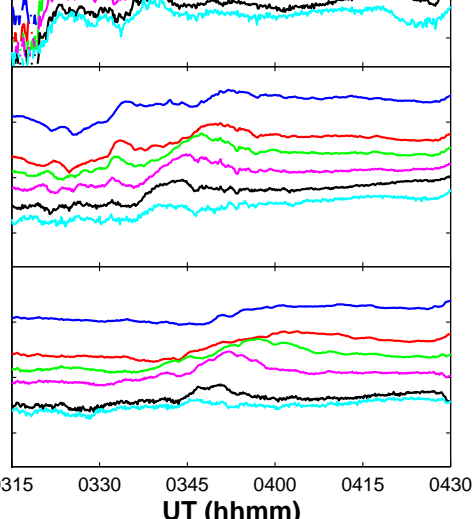

1990-095

$01 \mathrm{~A}$

$02 \mathrm{~A}$

$-225-315 \mathrm{keV}-315-500 \mathrm{keV}$

Fig. 5. Electron flux for particles with energies in the range of 50 to $500 \mathrm{keV}$ from the LANL satellites used in the study. Panel (a) shows data during the period of 14:00 UT to 15:15 UT on the 7 January 2005. Panel (b) shows data during the period of 22:15 UT to 23:30 UT on the 7 January 2005. Panel (c) shows data during the period of 03:15 UT to 04:30 UT on the 8 January 2005.

Lake, Pinawa and Fort Churchill, show the onset of a sustained period of CNA around $\sim 14: 26$ UT (at $\sim 06: 49$ MLT, $\sim 07: 34$ MLT and $\sim 07: 40$ MLT, respectively). Of the three riometers located above $70^{\circ} \mathrm{N}$ geomagnetic latitude (Rankin Inlet, Contwoyto and Taloyoak) only Contwoyto shows significant CNA during the substorm. However, the onset at this station does not occur until $\sim 14: 48$ UT ( $\sim 06: 31$ MLT), despite being the second most westerly station from the chain. The location of the riometers and the duration of the CNA indicate that this is likely to be Slowly Varying (Morning) Absorption (SVA) caused by the hardening of eastward drifting electrons from the substorm injection (e.g. Stauning, 1996, and references therein).

CNA is evident in IRIS and all SGO riometer stations except Jyväskylä after $\sim 14: 35$ UT ( 17:05-17:34 MLT at CNA onset). Jyväskylä is located at the lowest magnetic latitude of the $\mathrm{SGO}$ stations $\left(58.95^{\circ} \mathrm{N}, \mathrm{L} \approx 3.81\right)$. LANL satellites located eastward (LANL-02A) and westward (LANL-
01A) of the position of these riometers do not show an increase in electron flux intensities consistent with particle injection. They also do not show a significant variation across energy channels consistent with drifting particles at the time of the CNA.

The CNA is sporadic and exhibits a different temporal signature at each riometer station, although the profiles at Rovaniemi and Sodankylä $(30 \mathrm{MHz})$ are similar. The CNA appears to end following a peak that moves latitudinally northward from Rovaniemi (onset at $\sim 16: 05$ UT) to Kilpisjärvi (onset at $\sim 16: 35$ UT). CNA largely disappears at $\sim 16: 50$ UT. Some small impulsive CNA is seen at IRIS until 18:00 UT. IMAGE magnetometer observations (Fig. 9a) show disturbed conditions at all stations during the periods of CNA, from $\sim 14: 25$ UT. They show recovery from $\sim 16: 35$ UT, although minor fluctuations continue, consistent with the end of the CNA period. The disturbance originates at high latitude and propagates southward. The initial small 
SGO Riometers and IRIS Absorption: 7 to 8 January 2005

NORSTAR Riometers Absorption: 7 to 8 January 2005
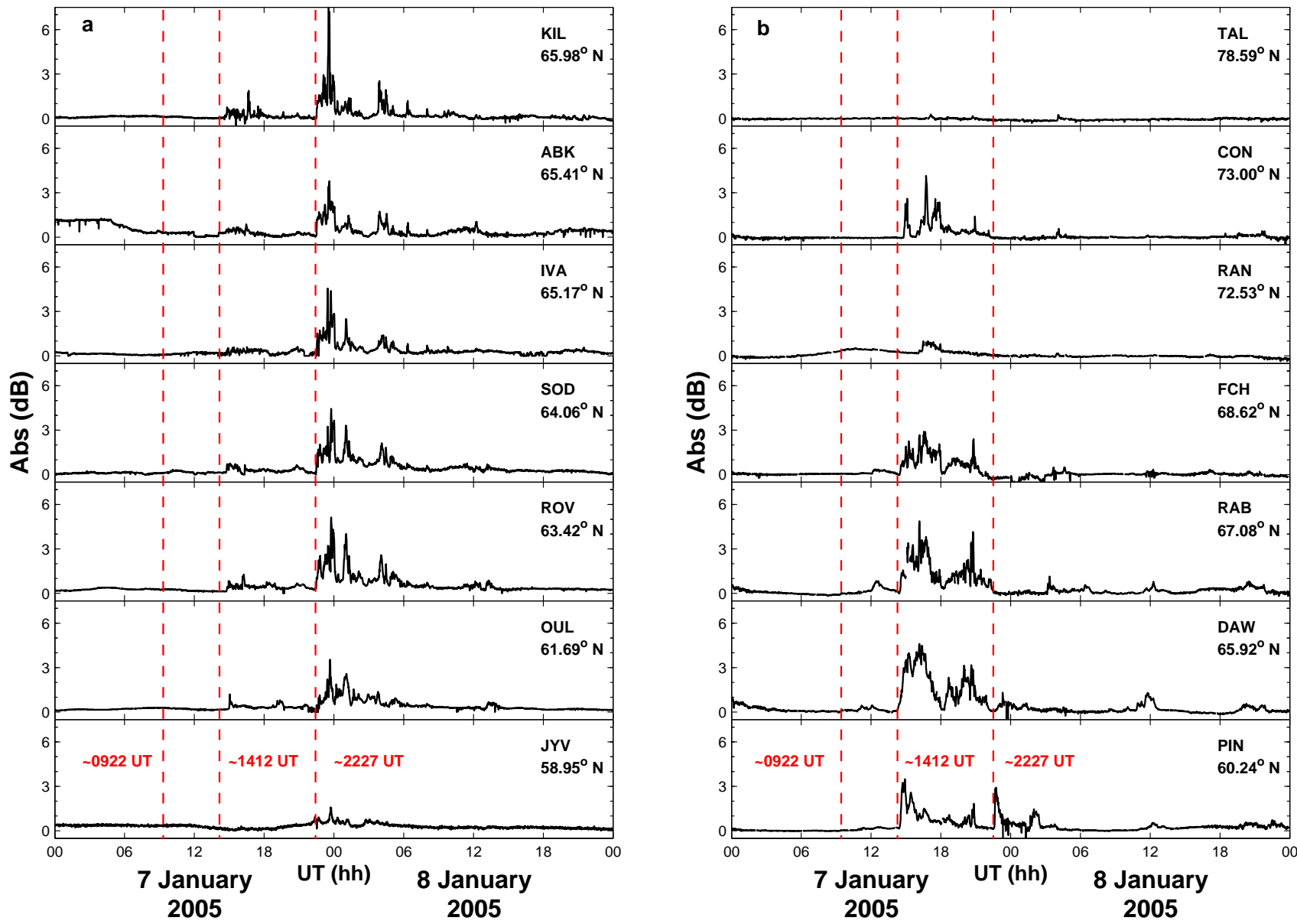

Fig. 6. Ionospheric CNA from the selected GLORIA stations on the 7 and 8 January 2005. The stations are ordered by descending magnetic latitude. Panel (a) shows data from the SGO riometers and IRIS at Kilpisjärvi. Panel (b) shows data from the NORSTAR riometers.

increase in CNA is associated with the appearance of the substorm current system overhead and precedes the increase in $P_{\text {dyn }}$; this may influence the subsequent increase in CNA but that is inconclusive. The lack of electron flux at the local LANL satellite can be explained if the electrons responsible for the absorption are of lower than usual energy and if the current system is confined earthward of geostationary orbit at that magnetic local time. Inspection of a north-south aligned row of beams in IRIS indicates that the CNA drops away with increasing latitude such that the footprint of geostationary orbit corresponds to essentially background CNA.

Variations in solar wind pressure can be observed at Geotail from $\sim 14: 30$ UT, with an impulse at $\sim 14: 57$ UT. These variations occur during the first period of substorm activity, when CNA is also observed at the SGO riometers and IRIS. The $P_{\mathrm{dyn}}$ increase is due to an increase in the proton number density of the solar wind rather than velocity and is highly variable. At this time, the $K_{p}$ index indicates active conditions $\left(K_{p} \geq 5\right)$.
The global geomagnetic field at this time can be investigated via the SYM-H index. An overall decrease in SYM$\mathrm{H}$ can be observed from the time of the substorm onset at $\sim 14: 12$ UT. Some deviations from the trend of SYM-H that seem to reflect changes in $P_{\text {dyn }}$ can be seen. However, there are many $P_{\text {dyn }}$ variations that appear to have no effect on SYM-H. The sudden decrease in $P_{\text {dyn }}$ observed by Geotail at $\sim 17: 56$ UT is mirrored by a sudden decrease in SYM-H at $\sim 18: 00 \mathrm{UT}$, indicating rapid expansion of the magnetosphere. The decreases in $P_{\text {dyn }}$ and SYM-H occur at the time at which the period of CNA also finally tails off at both chains of riometers and IRIS.

While the CNA at SGO and IRIS occurs during a period of $P_{\text {dyn }}$ variations, there is no evidence that the CNA is directly driven by $P_{\text {dyn }}$ at this time. For example, the most significant peak in CNA at IRIS, observed from 16:30 UT, does not correspond to an impulse in the $P_{\text {dyn }}$ or SYM-H index.

CNA related to magnetospheric compression is difficult to identify in the NORSTAR riometers, which are located in the 
IMAGE Magnetometers: 7 to 8 January 2005

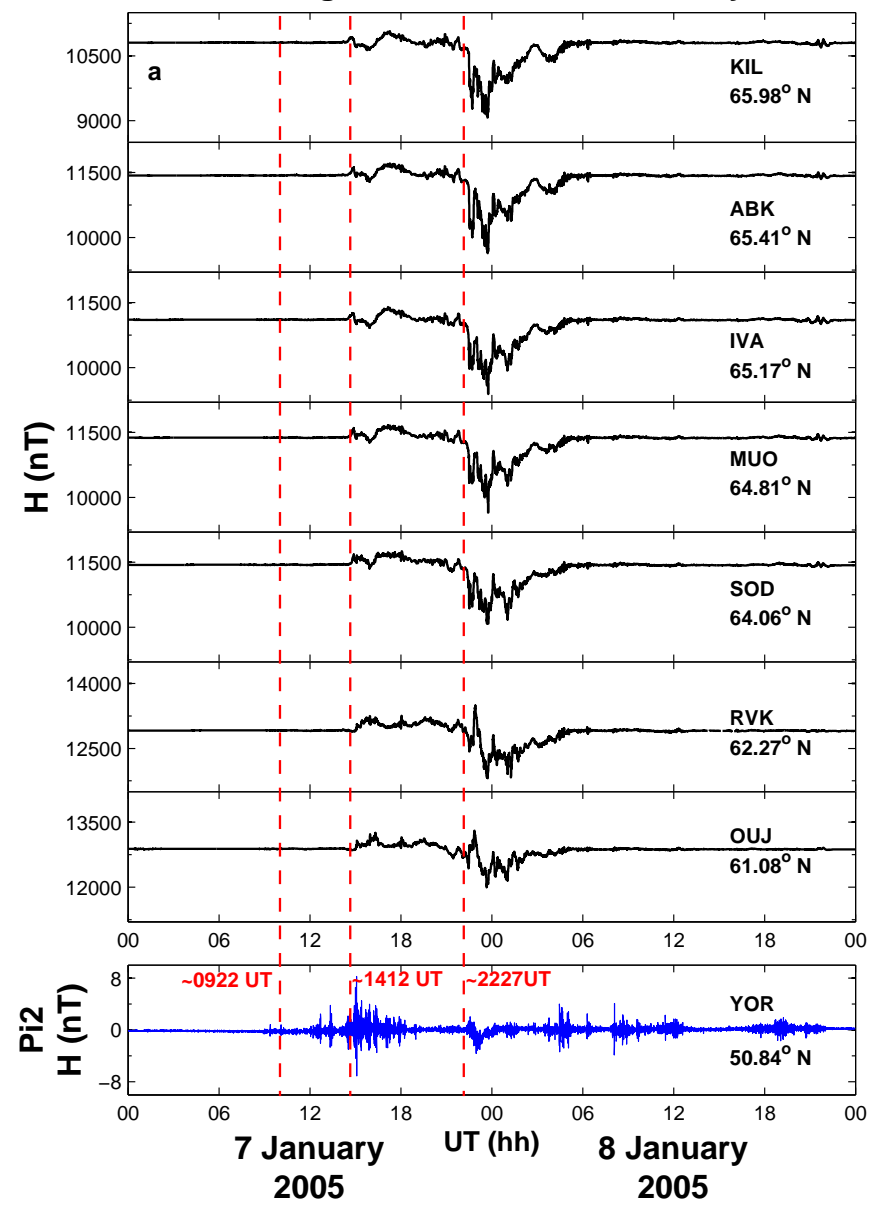

CARISMA Magnetometers: 7 to 8 January 2005
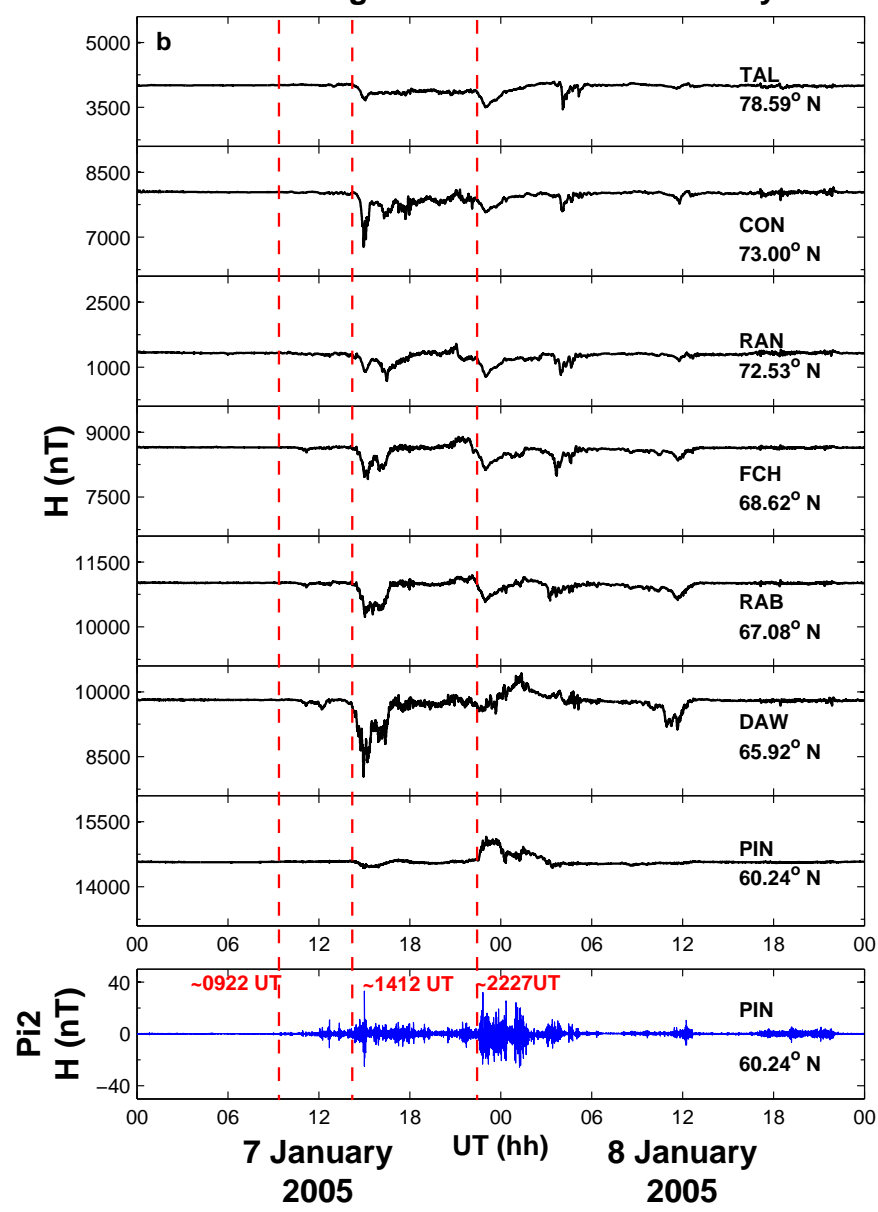

Fig. 7. The horizontal component of the geomagnetic field from ground based magnetometers on the 7 and 8 January 2005 . The stations are ordered by descending magnetic latitude. Panel (a) shows data from the IMAGE magnetometer chain. Panel (b) shows data from the CARISMA magnetometer chain. Pi2 filtered data are shown for the SAMNET York station and the CARISMA Pinawa station.

morning at this time, as the impulses occur during ongoing substorm related precipitation. Following the end of the substorm activity, CNA is still evident at some of the NORSTAR riometers at latitudes below $70^{\circ} \mathrm{N}$. However, this does not appear to be linked to $P_{\text {dyn }}$ variations as coincident impulses in SYM-H are not evident.

At $\sim 20: 30$ UT, a two-step increase in SYM-H of around $30 \mathrm{nT}$ is evident following a $P_{\mathrm{dyn}}$ decrease followed almost immediately by rapid increases. This coincides with a period of enhanced CNA at NORSTAR with multiple peaks. As precipitation is observed prior to the impulse, the CNA may simply be a continuation of the previous activity.

5.3 Precipitation during the second period of substorm activity

At the time of onset of the second period of substorm activity ( 22:27 UT on the 7 January 2005), the SGO riometers and IRIS were located post-midnight ( $\sim 00: 58-01: 26$ MLT) while the NORSTAR riometers were in the local afternoon ( 11:59-16:02 MLT). Figure 10 shows the CNA data for the event from 22:00 UT on the 7 January 2005 until 02:00 UT on the 8 January 2005, covering this period of activity. The IMAGE magnetometer data for this period is shown in Fig. $9 b$.

The SGO riometers (except Jyväskylä) and IRIS begin to show enhanced CNA from $\sim 22: 28$ UT. There is evidence of a rapid longitudinal motion westward in the CNA. It is first observed in the most easterly station, Ivalo, before progressing to the most westerly station, Abisko, after a time delay of the order of two minutes. This CNA occurs after the onset of the second period of substorm activity with the apparently dispersionless injection at $\sim 22: 27$ UT at LANL-02A (Fig. 5b).

The CNA remains enhanced (with discrete increases) from the start of the substorm activity until $\sim 14: 34$ UT on 8 January 2005. The signature is similar in riometers in which CNA is observed, although timings of individual features 
SGO Riometers and IRIS Absorption: 7 January 2005

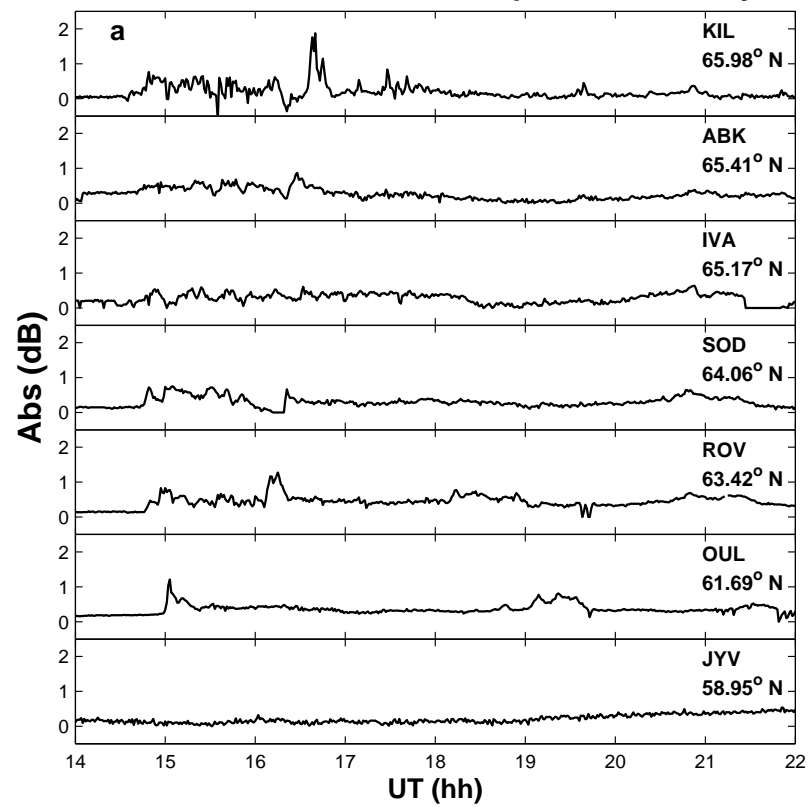

NORSTAR Riometers Absorption: 7 January 2005

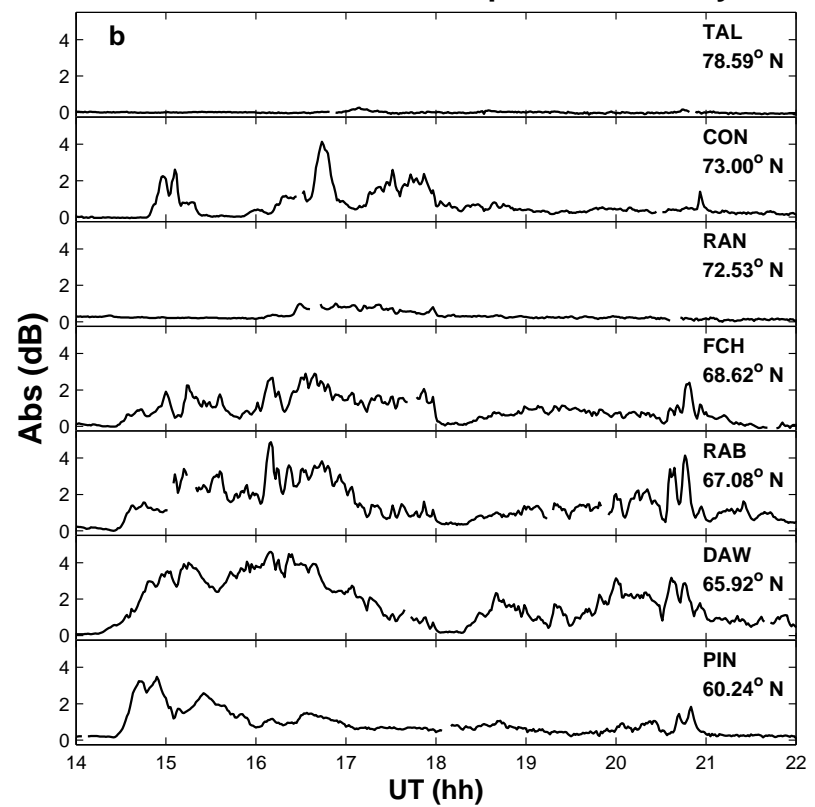

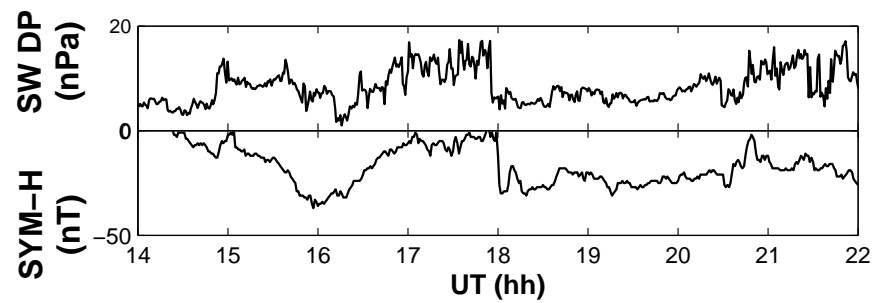

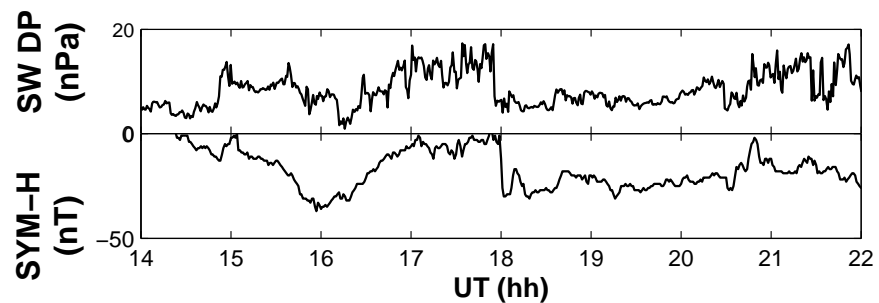

Fig. 8. Ionospheric CNA from the selected GLORIA stations during the period of 14:00 UT until 22:00 UT on the 7 January 2005. The stations are ordered by descending magnetic latitude. Panel (a) shows data from the SGO riometers and IRIS at Kilpisjärvi. Panel (b) shows data from the NORSTAR riometers. Solar wind dynamic pressure data from Geotail and the SYM-H index are shown at the bottom of each panel.

vary on a timescale of the order of five minutes. CNA is primarily seen at the higher latitude stations of the SGO chain and IRIS. However, between $\sim 23: 32$ and 23:55 UT, CNA reaching levels greater than $1.5 \mathrm{~dB}$ can even be seen at Jyväskylä. This indicates an expansion of the auroral oval to latitudes below $60^{\circ} \mathrm{N}$ during this time.

The CNA over Fennoscandia also coincides with local geomagnetic disturbances identified in the IMAGE magnetometer data (Fig. 9b). The later periods of CNA coincide with impulsive short-lived disturbances in the local geomagnetic field.

Prior to 23:30 UT on 7 January 2005, the global geomagnetic field in the form of the SYM-H index appears to be dominated by the effects of the substorm activity. After this, compression and expansion of the magnetic field can be seen following some of the large $P_{\mathrm{dyn}}$ pulses observed at Geotail.

Initially, while the riometers are located in the night sector, the precipitation appears to be directly related to the substorm activity. Much of this CNA occurs at times of elevated electron flux intensities observed by LANL-01A and 02A. During the progression of the substorms, $P_{\text {dyn }}$ is elevated and impulsive signatures in the SYM-H index appear coincident with CNA, for example at the time of CNA at Jyväskylä. However, at these times some riometers in the SGO chain and IRIS exhibit CNA prior to the impulse and so it is not possible to attribute the CNA to the impulse due to the ongoing precipitation.

Throughout this substorm, the NORSTAR riometers see little CNA. When CNA is present, it is at individual stations and is limited in time. The most significant CNA is recorded by Pinawa, the most equatorward of the riometers in the chain, with onset at $\sim 22: 35$ UT $(\sim 15: 57$ MLT $)$. There is evidence of enhanced electron flux at LANL-97A across all energy channels which does not exhibit a dispersed signature. The other NORSTAR riometers lying in a meridional chain with Pinawa do not show any enhancement in CNA at this time. Therefore it is unlikely to be the result of substorm related precipitation. Despite the impulsive profile, this CNA 
IMAGE Magnetometers: 7 January 2005
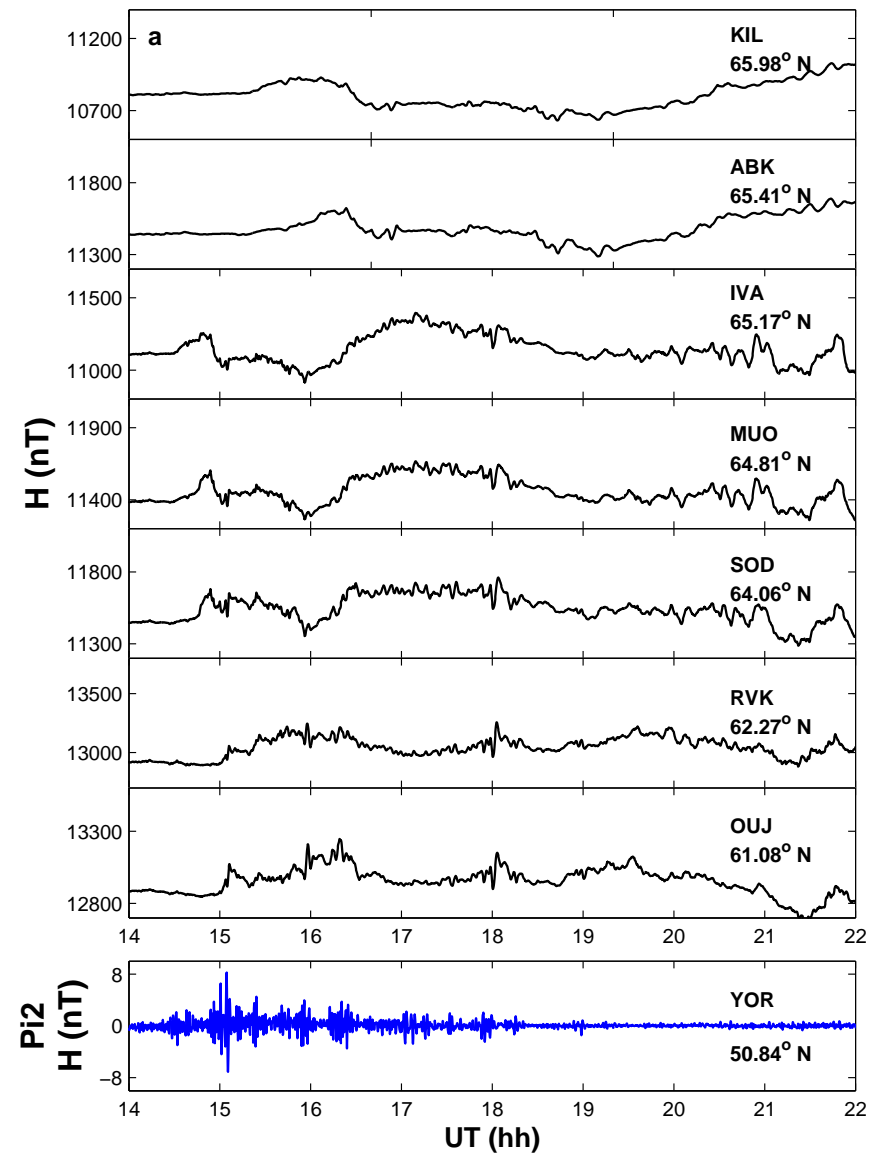

IMAGE Magnetometers: 7 to 8 January 2005
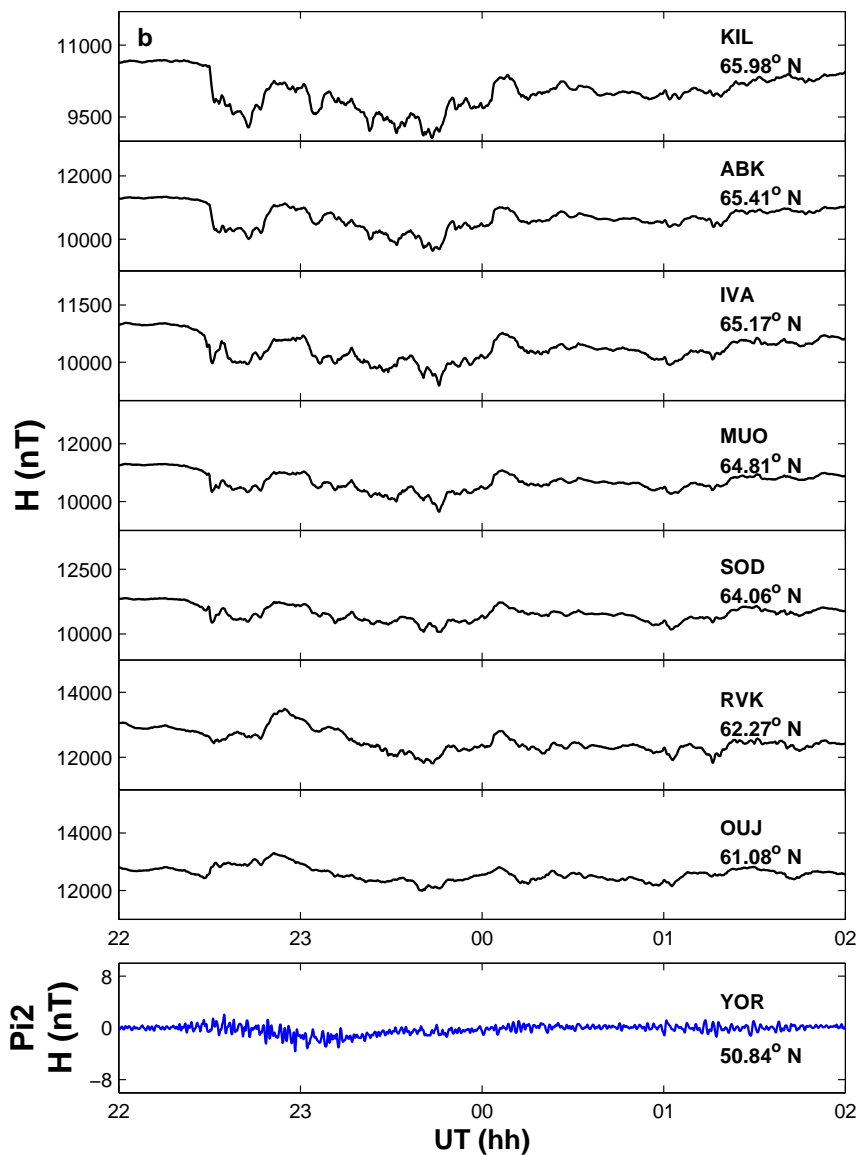

Fig. 9. The horizontal component of the geomagnetic field from selected IMAGE magnetometer stations. The stations are ordered by descending magnetic latitude. Panel (a) shows the data during the period of 14:00 UT until 22:00 UT on the 7 January 2005. Panel (b) shows the data during the period of 22:00 UT on the 7 January 2005 until 02:00 UT on the 8 January 2005. Pi2 filtered data are shown for the SAMNET York station.

is not coincident with $P_{\text {dyn }}$ variations and there is no impulse in SYM-H at this time, ruling out SIA. Dawson also observes CNA at $\sim 23: 16$ UT $(\sim 12: 48$ MLT) that is unrelated to impulses in SYM-H. Signatures of the substorm are clear in the IMAGE magnetometer data (Fig. 7). The second bay at $\sim 03: 45$ UT indicates a double onset or intensification but may simply be a continuation of the earlier substorm related precipitation.

\subsection{Precipitation following the substorm activity}

The last clear dispersionless injection signature indicating substorm activity was observed in the LANL SOPA electron flux intensity at $\sim 03: 33$ UT on the 8 January 2005 . Figure 11 shows the CNA data for the event from 04:00 UT until 10:00 UT on the 8 January 2005, covering the period following the previous activity. Instances of CNA are still evident at both chains of riometers. At this time, the effects of isolated instances of rapid magnetospheric compression on precipitation while geomagnetic activity is still high can be investigated.

For example, at $\sim 04: 19$ UT on the 8 January 2005 , the $P_{\text {dyn }}$ at Geotail began to rapidly increase, reaching a peak value of $\sim 39 \mathrm{nPa}$ at $\sim 04: 30 \mathrm{UT}$, an increase of over $30 \mathrm{nPa}$. This was followed by a $48 \mathrm{nT}$ positive impulse in SYM-H. The onset of the impulse in SYM-H occurred at $\sim 04: 21 \mathrm{UT}$, reaching a peak value at $\sim 04: 36 \mathrm{UT}$. At this time, $K_{p}$ was $6^{-}$, well above the activity threshold found by Osepian and Kirkwood (2004). Four of the SGO riometers show an increase in CNA simultaneously at $\sim 04: 22$ UT where they had previously shown recovery to quiet levels following the preceding activity. Two further riometers also show an increase in CNA from this time on a background of decreasing CNA. At the onset of this CNA, the riometers were located in the morning sector ( 06:53-07:21 MLT). CNA from this impulse can also be seen at the NORSTAR 
SGO Riometers and IRIS Absorption: 7 to 8 January 2005
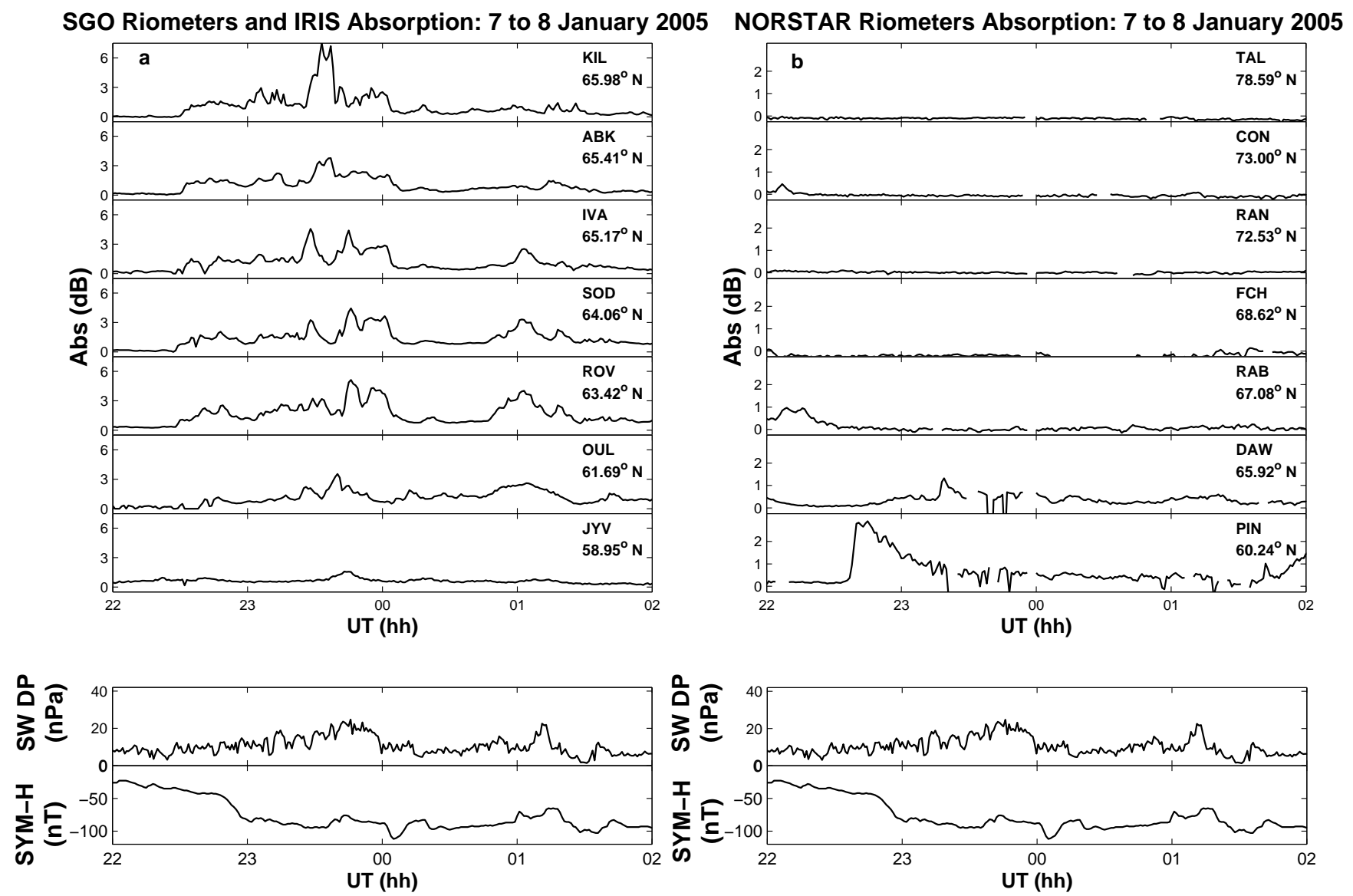

Fig. 10. Ionospheric CNA from the selected GLORIA stations during the period of 22:00 UT on the 7 until 02:00 UT on the 8 January 2005. The stations are ordered by descending magnetic latitude. Panel (a) shows data from the SGO riometers and IRIS at Kilpisjärvi. Panel (b) shows data from the NORSTAR riometers. Solar wind dynamic pressure data from Geotail and the SYM-H index are shown at the bottom of each panel.

riometers, located in the dusk-midnight sector. CNA increases occur simultaneously at Dawson $(\sim 18: 00$ MLT) and Churchill ( $\sim 21: 56$ MLT) at $\sim 04: 28$ UT. There is a slight delay ( $\sim \mathrm{min})$ at higher latitudes, for example at Rankin Inlet and Contwoyto. It should be noted that there is no longitudinal progression between stations. This appears to be evidence of global scale particle precipitation following a $P_{\text {dyn }}$ driven geomagnetic impulse.

A number of $P_{\text {dyn }}$ increases can be mapped to CNA increases at the SGO and IRIS riometers in this manner, with corresponding geomagnetic impulses in SYM-H. Therefore, it seems that the CNA observed from 04:22 UT, until $\sim 12: 45$ UT is SIA. However, no more clear examples of global scale SIA have been identified with particle precipitation evident in NORSTAR riometers as well, likely due to the local time positions of the instruments, under the magnetotail.
From Fig. 11, a period of excellent coincidence between dayside CNA, the SYM-H index and $P_{\mathrm{dyn}}$ at Geotail can be seen from 06:00 UT until 08:30 UT. Throughout this period, the SGO riometers and IRIS at Kilpisjärvi were at MLTs in the range $\sim 08: 31$ to $\sim 11: 29$ and so were ideally located to observe any SIA effects.

It should be noted that impulses in SYM-H are observed without coincident CNA at any riometers and CNA is seen on occasions without signatures of magnetospheric compression, indicating instances of both external and internal control of precipitation. Many of the impulses in SYM-H are small and have not been confirmed as Sudden Impulses. However, the observations of CNA relative the timing of impulses in SYM-H imply that SIs will not always induce SIA when they occur during active periods. In the Osepian and Kirkwood (2004) study, 88.2\% of storm SCs observed during an active period resulted in SCA at a single riometer (Loparskaya, $\mathrm{L} \approx 5.3$ ). The impulses during the geomagnetic 
SGO Riometers and IRIS Absorption: 8 January 2005

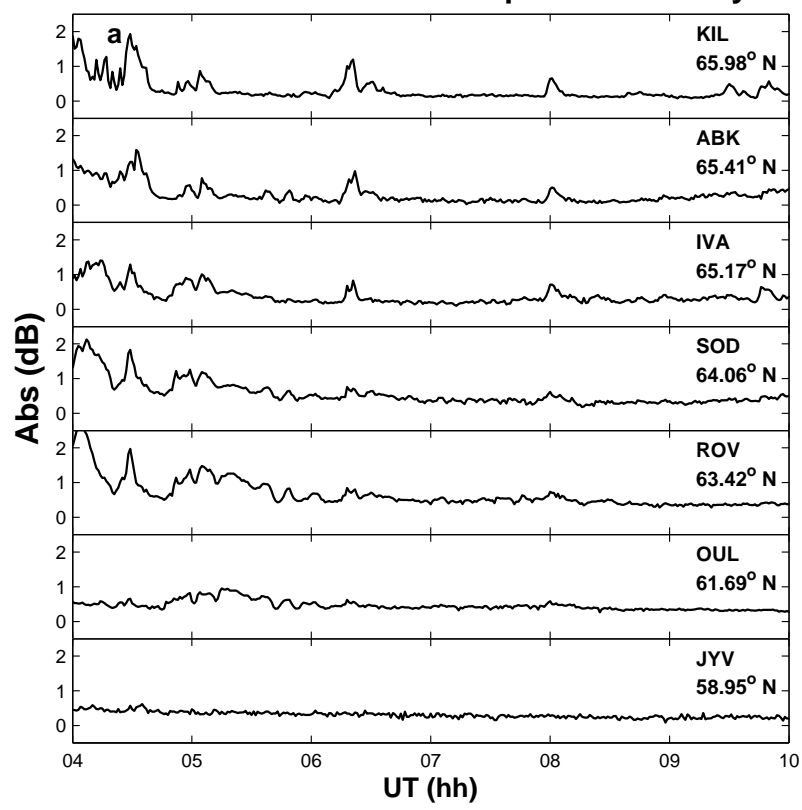

NORSTAR Riometers Absorption: 8 January 2005

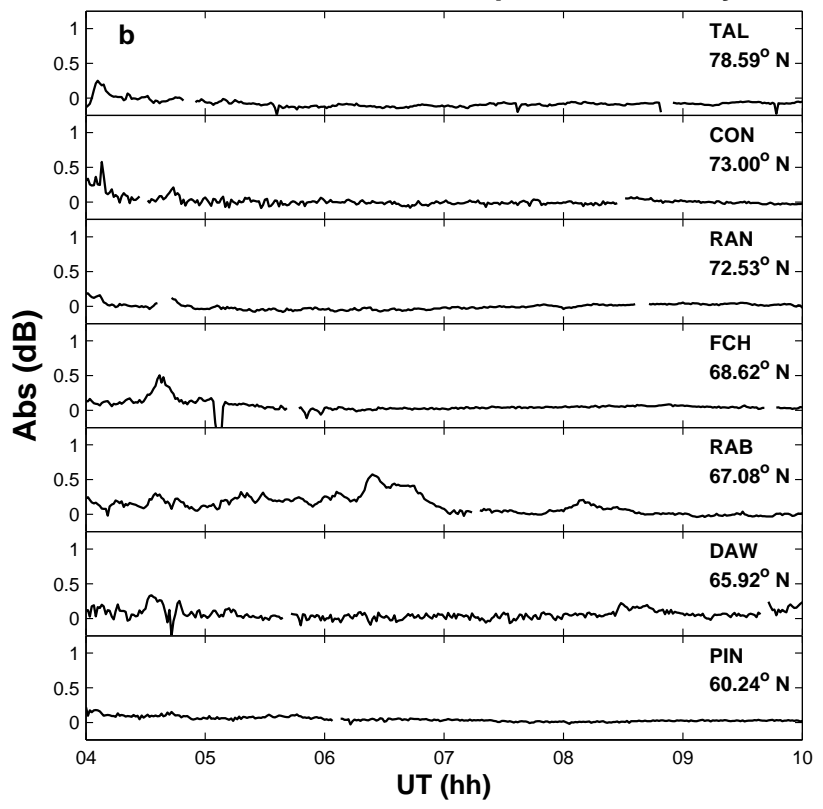

空唡

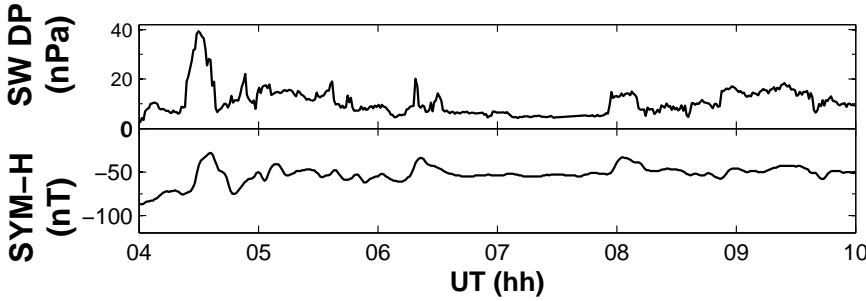

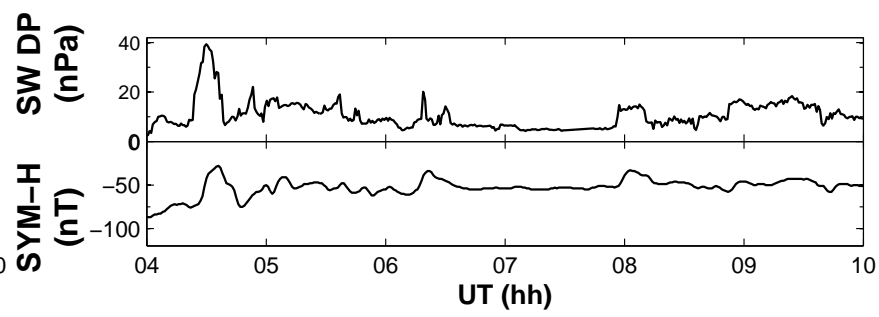

Fig. 11. Ionospheric CNA from the selected GLORIA stations during the period of 04:00 UT until 10:00 UT on the 8 January 2005. The stations are ordered by descending magnetic latitude. Panel (a) shows data from the SGO riometers and IRIS at Kilpisjärvi. Panel (b) shows data from the NORSTAR riometers. Solar wind dynamic pressure data from Geotail and the SYM-H index are shown at the bottom of each panel.

storm of the 7 and 8 January 2005 differ from storm SCs as they are not isolated incidents and occur during ongoing geomagnetic activity. Also, the storm SCs are related to the passage of interplanetary shocks whereas the impulses during this ICME are due to $P_{\mathrm{dyn}}$ variations, controlled by changes in density.

At the time of the $P_{\text {dyn }}$ pulses coincident with CNA, the electron flux intensity at the LANL satellites show small increases simultaneously across all energy channels. Studies conducted have shown a broad correlation between geosynchronous electron flux intensity and CNA during substorms (e.g. Parks et al., 1968; Arnoldy and Chan, 1969; Rosen and Winckler, 1970). Baker et al. (1981) present a number of events where riometers record CNA rises at the time of geosynchronous flux intensity increases at conjugate LANL satellites during the near midnight and morning sectors, again during substorms.

\section{Summary and conclusions}

We have presented a case study of energetic electron precipitation during a moderate geomagnetic storm driven by the passage of an ICME. Observations were made by riometers in Canada and Fennoscandia that comprise part of GLORIA; the locations of the instruments at the time of the storm onset were particularly advantageous for studying both external and internal precipitation trigger mechanisms during the period of elevated geomagnetic activity.

The storm that began on 7 January 2005 was prefaced by a period of very low geomagnetic activity, leaving the magnetosphere in an unprimed state in terms of the trapped electron population. A small increase in solar wind dynamic pressure led to a weak sudden commencement as recorded by mid and low latitude magnetometers. Riometers located close to local noon recorded zero increases in CNA; this is consistent with the findings of Osepian and Kirkwood (2004). 
CNA was only observed following periods of enhanced IMF-magnetosphere coupling (as indicated by negative $B_{z}$ ) which led to substorm activity with associated injections of electrons into the inner magnetosphere. An increase in CNA close to dusk has been associated with the westward edge of the substorm current system rather than a coincident small increase in $P_{\mathrm{dyn}}$. Subsequent larger steps in the pressure might affect the precipitation but the observations are inconclusive.

Much of the CNA observed during the storm was linked to substorm activity, through the precipitation of freshly injected electrons or following gradient curvature drift. However, additional absorption directly driven by solar wind conditions was also observed. During the recovery phase of the storm, substorm activity diminished and the effect of changes in $P_{\text {dyn }}$ on CNA could be determined. For an impulse at $\sim 04: 20$ UT, riometers in both the post-dawn and dusk-midnight sectors recorded a response; the rise time was similar for all instruments indicating a global response to the pressure enhancement.

Between 04:00 and 12:00 UT the dayside riometers record a good correlation with the SYM-H index; although not all impulses recorded in SYM-H show a corresponding absorption signature. The nightside riometers do not show any further enhancements. Thus solar wind density-controlled SIs during the recovery phase of a storm can produce a very different precipitation response to typical SCs.

Acknowledgements. The authors wish to thank M. Denton for useful conversations. The ACE and Geotail solar wind and IMF data were obtained from the NASA CDAWeb (http://cdaweb.gsfc.nasa. gov). The data originated from the Imaging Riometer for Ionospheric Studies (IRIS), operated by the Department of Communications Systems at Lancaster University (UK) in collaboration with the Sodankylä Geophysical Observatory, and is funded by the Science and Technology Facilities Council (STFC, formerly PPARC). The NORSTAR riometer project is supported by the Canadian Space Agency. We are grateful to E. Spanswick who baselined the NORSTAR data used in this study. We thank the institutes who maintain the IMAGE magnetometer array and the Finnish Meteorological Institute; the IMAGE magnetometer data are collected as a joint European collaboration. The authors thank the SAMNET team for magnetometer data. SAMNET is operated by Lancaster University and funded by STFC (formerly PPARC). The authors thank I. R. Mann and the CARISMA team for data. CARISMA is operated by the University of Alberta with support from the Canadian Space Agency. The $D_{s t}$ and $K_{p}$ indices data were obtained from NOAA's Space Physics Interactive Data Resources (http://spidr.ngdc.noaa.gov). The SYM-H and auroral electrojet indices data were obtained from the Kyoto World Data Center for Geomagnetism (http://swdcdb.kugi.kyoto-u.ac.jp). We thank Dot DeLapp and team at LANL for providing the SOPA data.

Topical Editor I. A. Daglis thanks M. Jarvis and another anonymous referee for their help in evaluating this paper.

\section{References}

Araki, T.: Global structure of geomagnetic sudden commencements, Planet. Space Sci., 25, 373-384, 1977.

Arnoldy, R. and Chan, K.: Particle substorms observed at the geostationary orbit, J. Geophys. Res., 74, 5019-5028, 1969.

Baker, D., Stauning P., Hones Jr., E., Higbie, P., and Belian, R.: Near-equatorial, high-resolution measurements of electron precipitation at L乞6.6, J. Geophys. Res., 86(A4), 2295-2313, 1981.

Belian, R., Gisler, G., Cayton, T., and Christensen, R.: High-Z energetic particles at geosynchronous orbit during the great solar proton event series of October 1989, J. Geophys. Res., 97, $16897-$ 16906, 1992.

Borovsky, J. and Denton, M.: Differences between CME-driven Storms and CIR-driven Storms, J. Geophys. Res., 111, A07S08, doi:10.1029/2005JA011447, 2006.

Brown, R.: On the poleward expansion of ionospheric absorption regions triggered by sudden commencements of geomagnetic storms, J. Geophys. Res., 83(A3), 1169-1171, 1978.

Brown, R., Hartz, T., Landmark, B., Leinbach, H., and Ortner, J.: Large-scale electron bombardment of the atmosphere at the sudden commencement of a geomagnetic storm, J. Geophys. Res., 66, 1035-1041, 1961.

Brown, R., Leinbach, H., Akasofu, S.-I., Driatsky, V., and Schmidt, R.: Quadruple conjugate pair observations of the sudden commencement absorption event on June 17, 1965, J. Geophys. Res., 77, 5602-5607, 1972.

Burch, J.: Preconditions for the triggering of polar magnetic substorms by storm sudden commencements, J. Geophys. Res., 77, 5629-5632, 1972.

Denton, M., Borovsky, J., Skoug, R., Thomsen, M., Lavraud, B., Henderson, M., McPherron, R., Zhang, J., and Liemohn, M.: Geomagnetic storms driven by ICME- and CIRdominated solar wind, J. Geophys. Res., 111, A07S07, doi:10.1029/2005JA011436, 2006.

Frank, L., Ackerson, K., Paterson, W., Lee, J., English, M., and Pickett, G.: The Comprehensive Plasma Instrumentation (CPI) for the GEOTAIL spacecraft, J. Geomagn. Geoelectr., 46, 23-37, 1994.

Gonzalez, W., Joselyn, J., Kamide, Y., Kroehl, H., Rostoker, G., Tsurutani, B., and Vasyliunas, V.: What is a geomagnetic storm?, J. Geophys. Res., 99, 5771-5792, 1994.

Gosling, J., McComas, D., Phillips, J., and Bame, J.: Geomagnetic activity associated with Earth passage of interplanetary shock disturbances and coronal mass ejections, J. Geophys. Res., 96, 7831-7839, 1991.

Hargreaves, J.: Auroral absorption of HF radio waves in the ionosphere: A review of results from the first decade of riometry, P. IEEE, 57, 1348-1373, 1969.

Hargreaves, J.: The Solar-Terrestrial Environment, Cambridge University Press, 1992.

Kamide, Y., Yokoyama, N., Gonzalez, W., Tsurutani, B., Daglis, I., Brekke, A., and Masuda, S.: Two step development of geomagnetic storms, J. Geophys. Res., 103, 6917-6921, 1998.

Khan, H. and Cowley, S.: Observations of the response time of high-latitude ionospheric convection to variations in the interplanetary magnetic field using EISCAT and IMP-8 Data, Ann. Geophys., 17, 1306-1335, 1999, http://www.ann-geophys.net/17/1306/1999/.

Kokubun, S., Yamamoto, T., Acuna, M., Hayashi, K., Shiokawa, K., 
and Kawano, H.: The GEOTAIL Magnetic Field Experiment, J. Geomagn. Geoelectr., 46, 7-21, 1994.

Maus, S., MacMillan, S., Chernova, T., Choi, S., Dater, D., Golovkov, V., Lesur, V., Lowes, F., Lühr, H., Mai, W., McLean, S., Olsen, N., Rother, M., Sabaka, T., Thomson, A., and Zvereva, T.: The 10th generation international geomagnetic reference field, Phys. Earth Planet. In., 151, 320322, 2005.

McComas, D., Bame, S., Barker, P., Feldman, W., Phillips, J., Riley, P., and Griffee, J.: Solar Wind Electron Proton Alpha Monitor (SWEPAM) for the Advanced Composition Explorer, Space Sci. Rev., 86, 563-612, 1998.

Ortner, J., Hultqvist, B., Brown, R., Hartz, T., Holt, O., Landmark, B., Hook, J., and Leinbach, H.: Cosmic noise absorption accompanying geomagnetic storm sudden commencements, J. Geophys. Res., 67, 4169-4186, 1962.

Osepian, A. and Kirkwood, S.: Cosmic radio-noise absorption bursts caused by solar wind shocks, Ann. Geophys., 22, 29732987, 2004, http://www.ann-geophys.net/22/2973/2004/.

Parks, G., Arnoldy, R., Lezniak, T., and Winckler, J.: Correlated effects of energetic electrons at the $6.6 R_{e}$ equator and the auroral zone during magnetospheric substorms, Radio Sci., 3, 715-719, 1968.

Perona, G.: Theory on the precipitation of magnetospheric electrons at the time of sudden commencement, J. Geophys. Res., 77, 101$111,1972$.
Richardson, I., Cliver, E., and Cane, H.: Sources of geomagnetic storms for solar minimum and maximum conditions during 1972-2000, Geophys. Res. Lett., 28, 2567-2572, 2001.

Rosen, L. and Winckler, J.: Evidence for the large-scale azimuthal drift of electron precipitation during magnetospheric substorms, J. Geophys. Res., 75, 5576-5581, 1970.

Smith, C., L'Heureux, J., Ness, N., Acuña, M., Burlaga, L., and Scheifele, J.: The ACE Magnetic Fields Experiment, Space Sci. Rev., 86, 613-632, 1998.

Stauning, P.: Investigations of ionospheric radio wave absorption processes using imaging riometer techniques, J. Atmos. Terr. Phys., 58, 753-764, 1996.

Takeuchi, T., Araki, T., Viljanen, A., and Watermann, J.: Geomagnetic negative sudden impulses: Interplanetary causes and polarization distribution, J. Geophys. Res., 107, A7, doi:10.1029/2001JA900152, 2002.

Taylor, J., Lester, M., and Yeoman, T.: A superposed epoch analysis of geomagnetic storms, Ann. Geophys., 12, 612-624, 1994, http://www.ann-geophys.net/12/612/1994/.

Tsyganenko, N.: Modeling the Earth's magnetospheric field confined within a realistic magnetospause, J. Geophys. Res., 100, 5599-5612, 1995.

Wanliss, J. and Showalter, K.: High-resolution global storm index: $D_{s t}$ versus SYM-H, J. Geophys. Res., 111, A02202, doi:10.1029/2005JA011034, 2006. 